\title{
Interaction Between $\alpha$ CaMKII and GluN2B Controls ERK-Dependent Plasticity
}

\author{
Farida El Gaamouch, ${ }^{1,4}$ Alain Buisson, ${ }^{1,3}$ Olivier Moustié, ${ }^{1}$ Mado Lemieux, ${ }^{4}$ Simon Labrecque, ${ }^{4}$ Bruno Bontempi, ${ }^{2}$ \\ Paul De Koninck, ${ }^{4,5}$ and Olivier Nicole ${ }^{1,2}$ \\ ${ }^{1}$ Université de Caen-Basse Normandie, CNRS UMR 6232, CINAPS-PSY, 14000 Caen, France, ${ }^{2}$ Université Bordeaux, CNRS - Institut des Maladies \\ Neurodégénératives, UMR5293, F-33000 Bordeaux, France, ${ }^{3}$ Centre de Recherche Inserm U 836 - UJF - CEA - CHU, Université Joseph Fourier - Site Santé, \\ 38706 La Tronche Cedex, France, ${ }^{4}$ Institut universitaire de santé mentale de Québec, Québec G1J 2G3 Canada, and ${ }^{5}$ Département de biochimie, \\ microbiologie et bio-informatique, Université Laval, Québec G1T 1H2, Canada
}

Understanding how brief synaptic events can lead to sustained changes in synaptic structure and strength is a necessary step in solving the rules governing learning and memory. Activation of ERK1/2 (extracellular signal regulated protein kinase 1/2) plays a key role in the control of functional and structural synaptic plasticity. One of the triggering events that activates ERK1/2 cascade is an NMDA receptor (NMDAR)-dependent rise in free intracellular $\mathrm{Ca}^{2+}$ concentration. However the mechanism by which a short-lasting rise in $\mathrm{Ca}^{2+}$ concentration is transduced into long-lasting ERK1/2-dependent plasticity remains unknown. Here we demonstrate that although synaptic activation in mouse cultured cortical neurons induces intracellular $\mathrm{Ca}^{2+}$ elevation via both GluN2A and GluN2B-containing NMDARs, only GluN2B-containing NMDAR activation leads to a long-lasting ERK1/2 phosphorylation. We show that $\alpha$ CaMKII, but not $\beta C a M K I I$, is critically involved in this GluN2B-dependent activation of ERK1/2 signaling, through a direct interaction between GluN2B and $\alpha$ CaMKII. We then show that interfering with GluN2B/ $\alpha$ CaMKII interaction prevents synaptic activity from inducing ERKdependent increases in synaptic AMPA receptors and spine volume. Thus, in a developing circuit model, the brief activity of synaptic GluN2B-containing receptors and the interaction between GluN2B and $\alpha$ CaMKII have a role in long-term plasticity via the control of ERK1/2 signaling. Our findings suggest that the roles that these major molecular elements have in learning and memory may operate through a common pathway.

\section{Introduction}

One key neurobiological mechanism underlying the formation and storage of memory resides in activity-driven modifications of synaptic strength and structural remodeling of synapses. Over the past decade, the ERK/MAPK (extracellular signal-regulated protein kinase/mitogen-activated protein kinase) pathway has emerged as a central player in the signaling mechanisms involved in the activity-driven synaptic changes. A significant contribution of ERK1/2 to synaptic plasticity and memory formation in

Received Nov. 8, 2011; revised June 5, 2012; accepted June 11, 2012.

Author contributions: F.E.G., A.B., 0.M., M.L., S.L., P.D.K., and 0.N. designed research; F.E.G., O.M., M.L., S.L., and O.N. performed research; B.B. contributed unpublished reagents/analytic tools; F.E.G., O.M., M.L., S.L., P.D.K., and O.N. analyzed data; F.E.G., A.B., B.B., P.D.K., and O.N. wrote the paper.

This work was supported by grants from the French Ministry of Research, Alzheimer Foundation, the Agence National de la Recherche (ANR MALZ 2010-001-02 CoRehAlz to B.B.), and Regional Council of Basse-Normandie France (F.E.G., O.N., A.B.), and the Canadian Institutes of Health Research (CIHR) (P.D.K.). M.L. has been supported by studentships from the Natural Science and Engineering Research Council of Canada (NSERC), CIHR, and the Fond de la Recherche en Santé du Québec. S.L. was supported by a CIHR Neurophysics training grant. P.D.K. was a career awardee of CIHR. We thank Francine Nault for preparing the neuronal cultures and David Lemelin for recombinant DNA constructions, and Kevin Dion and Karim Bordji for technical and experimental assistance. We thank Emilie Pacary for critical discussion and suggestions.

The authors declare no competing financial interests.

Correspondence should be addressed to either of the following: Dr. Olivier Nicole, CNRS UMR 5293 - Institut des Maladies Neurodégénératives, Université Victor Segalen, Bordeaux2, BP 28146 rue Léo Saignat, 33076 Bordeaux cedex, France, E-mail: olivier.nicole@u-bordeaux2.fr; or Dr. Paul De Koninck, Institut universitaire de santé mentale de Québec, 2601, Chemin de la Canardière, QC G1J 2G3, Canada, E-mail: paul.dekoninck@neurosciences.ulaval.ca. DOI:10.1523/JNEUROSCI.5622-11.2012

Copyright $\odot 2012$ the authors $\quad 0270-6474 / 12 / 3210767-13 \$ 15.00 / 0$ the adult brain has been established in several behavioral and cellular studies (Sweatt, 2004; Thomas and Huganir, 2004). Direct evidences supporting a role of ERK1/2 signaling pathway in memory described a prolonged pattern of ERK1/2 activation, lasting several hours after training completion (for review, see Sweatt, 2004). The prolonged ERK1/2 activation regulates AMPA receptor (AMPAR) trafficking and promotes structural modifications not only in activated dendritic spines but also in the neighborhood of recently potentiated spines (Patterson et al., 2010). ERK1/2 can also translocate into the nucleus to regulate histone phosphorylation and transcription factors such as CREB (cAMP response element-binding protein) and Elk-1 which initiate transcription of memory-associated genes (Chwang et al., 2006).

One of the signaling events that activates ERK $1 / 2$ cascade in synaptic plasticity is a rise in intracellular free $\mathrm{Ca}^{2+}$ concentration through NMDA receptors (NMDARs; Bading and Greenberg, 1991). Most native NMDARs are heterotetrameric assemblies composed of two glycine-binding GluN1 and two glutamate-binding GluN2. GluN2 subunits confer distinct gating and pharmacological properties to NMDARs (Traynelis et al., 2010). In addition, their cytoplasmic tails have distinct features allowing each subunit to engage in different signaling pathways (Köhr, 2006). Some of these features may specify the impact of the receptor on synaptic plasticity (Foster et al., 2010) and neurotoxicity (Xiao et al., 2011). Meanwhile, studies addressing the 
role of NMDAR subunit composition in ERK1/2 signaling pathway in synaptic plasticity and memory have yielded seemingly contrary results. For example, it was reported that GluN2B, but not GluN2A, is associated with RasGRF1 activation (Krapivinsky et al., 2003), and it was demonstrated that GluN2B can block the epilepsy-induced ERK1/2 activation in vivo (Chen et al., 2007). Those studies are consistent with the coupling of GluN2Bcontaining NMDARs with ERK1/2 activation. By contrast, other reports suggest a specific coupling of GluN2B-containing NMDARs to ERK1/2 inhibition (Kim et al., 2005) or the specific coupling of GluN2A-containing NMDARs to ERK1/2 activation (Jin and Feig, 2010). Thus, the link between NMDAR subunit composition and ERK1/2 signaling requires more investigation. Furthermore, the mechanism by which NMDAR-mediated transient elevation in $\mathrm{Ca}^{2+}$ concentration induces long-lasting synaptic changes is still unknown. In this context, the interactions of different GluN2 subunits with $\mathrm{Ca}^{2+}$ signaling proteins, such as $\mathrm{Ca}^{2+} /$ Calmodulin-dependent protein kinases (CaMKs), should be examined in NMDAR-mediated ERK1/2 signaling during synaptic plasticity.

To address this issue, we determined the NMDAR subunit and CaMKII isoform involved in ERK1/2 activation following synaptic NMDAR activation in cultured cortical neurons. We show that synaptic GluN2B-containing NMDAR activation leads to the recruitment of $\alpha$ CaMKII at the synapse, facilitating its interaction with GluN2B and thus triggering ERK phosphorylation. We provide evidence that the interaction between GluN2B and $\alpha$ CaMKII could be the critical step leading to a prolonged ERK1/2 phosphorylation beyond the stimulation duration necessary to trigger functional and structural modifications of glutamatergic synapses.

\section{Materials and Methods \\ Materials}

Antibodies against phosphorylated form of ERKs ( p-ERK), synaptophysin (SYP), GluN1 and total CaMKII were purchased from Santa Cruz Biotechnology, the antibody against ERKs from Cell Signaling Technology and the antibody against PSD-95 from Zymed. Pluronic acid, Alexa 555-conjugated anti-mouse and Fura-2/AM were purchased from Invitrogen.

\section{Chemicals}

BAPTA-AM was from Invitrogen, cytosine $\beta$-D-arabinofuranoside (Ara C), MK-801, D-APV, tetrodotoxin (TTX), 4-aminopyridine (4AP), Ifenprodil, STO-609, KN-93 were purchased from Tocris Bioscience, Bicuculline methiodide and $\alpha$ CaMKII shRNA lentiviral transduction particles were from Sigma-Aldrich. NVP-AAM077 was kindly provided by Dr. Yves Auberson (Novartis Institutes for BioMedical Research). The specific CaMKII inhibitor CN21a was generously provided by Dr K. U. Bayer (University of Colorado).

\section{Cell cultures}

Rat or mice primary cortical cultures were prepared as previously described (Rose et al., 1993; Hudmon et al., 2005). Cultures were kept at $37^{\circ} \mathrm{C}$ in a humidified atmosphere containing $5 \% \mathrm{CO}_{2}$. After $3 \mathrm{~d}$ in vitro (DIV), non-neuronal cell division was halted with $10 \mu \mathrm{M}$ Ara C. Media was then refreshed (50\%; without Ara C) twice a week and all experiments were performed at approximately DIV 14.

\section{Preparation}

Mice (C57B/L6J males, 3 months old) were anesthetized with halothane and decapitated. Brains were removed rapidly and submerged in an icecold artificial CSF (aCSF) of the following composition (in $\mathrm{mm}$ ): 130 $\mathrm{NaCl}, 24 \mathrm{NaHCO}_{3}, 3.5 \mathrm{KCl}, 1.25 \mathrm{NaH}_{2} \mathrm{PO}_{4}, 1 \mathrm{CaCl}_{2}, 3 \mathrm{MgCl}_{2}$, and 10 glucose saturated with $95 \% \mathrm{O}_{2} / 5 \% \mathrm{CO}_{2}, \mathrm{pH}$ 7.4. Hemisected brains were cut with a tissue chopper $(300 \mu \mathrm{m})$. Isolated sections were in an incubation chamber continuously equilibrated with $95 \% \mathrm{O}_{2} / 5 \% \mathrm{CO}_{2}$ and con- taining $124 \mathrm{~mm} \mathrm{NaCl}, 24 \mathrm{~mm} \mathrm{NaHCO}$, $3.5 \mathrm{~mm} \mathrm{KCl}, 1.5 \mathrm{~mm} \mathrm{CaCl}_{2}, 1.5$ $\mathrm{mm} \mathrm{MgCl}, 1.25 \mathrm{~mm} \mathrm{NaH}_{2} \mathrm{PO}_{4}$, and $10 \mathrm{~mm}$ glucose for $\sim 1 \mathrm{~h}$ before drug applications. Bicuculline (Bic)/4AP was added in the solution for $30 \mathrm{~min}$. Cortical regions were dissected from the slices and transferred to lysis buffer for p-ERK and ERK analysis.

\section{Synaptic NMDAR activation}

To activate synaptic NMDARs, we used a stimulation paradigm that we have previously characterized on cortical neurons (Gouix et al., 2009). Coapplication of bicuculline $(50 \mu \mathrm{M})$, a GABAA receptor antagonist, and 4AP (2.5 mM), a weak potassium-channel blocker, induces synchronous bursts of action potentials leading to synaptic NMDAR activation (Hardingham and Bading, 2002).

\section{Immunocytochemistry}

Immunocytochemistry was performed as described by Gouix et al. (2009). To evaluate the proportion of p-ERK-positive neurons, we performed colabeling for p-ERK (1:100; Santa Cruz Biotechnology) and a neuronal marker (1:500; Sigma-Aldrich). Images were taken with a Nikon Eclipse (TE2000-E) inverted C1 confocal microscope equipped with an oil-immersion Nikon $60 \times$ objective with 1.4 numerical aperture. Image acquisition parameters were fixed in the control condition to have a fluorescent signal close to background. Fluorescent images of MAP2 and $\mathrm{p}$-ERK were then acquired in bicuculline/4AP (Bic/4AP) conditions with the same image acquisition parameters. Five randomly chosen optical fields were analyzed from each experiment (15-20 neurons per field, for three independent wells). This analysis (Fig. 1A) was performed to estimate the proportion of MAP2 neurons that were also p-ERK, positive with or without Bic/4AP stimulation. The quantification of p-ERK levels from population of neurons under these conditions was done by Western blot.

For the analysis of p-ERK staining intensity in transfected neuronal cells, a binary mask was created from eGFP-positive cells. Then p-ERK intensity was analyzed in regions overlapping with the binary mask. Acquisition parameters were identical for every set of experiments. Data were normalized to the mean value of $\mathrm{p}$-ERK in neurons stimulated with $\mathrm{Bic} / 4 \mathrm{AP}$.

\section{Subcellular fractionation}

Postsynaptic density (PSD, also called Triton-resistant fraction) and non-PSD (also referred to as the Triton-sensitive fraction) preparations from cultured cortical neurons were performed as described by Pacchioni et al. (2009). Membranes were incubated with the following primary antibodies at $4^{\circ} \mathrm{C}$ overnight under gentle agitation: p-ERK, ERK, GluN1, SYP, PSD-95, CaMKII, actin at concentrations provided by the supplier.

\section{Immunoblotting}

Immunoblotting experiments were performed according to the protocol described by Léveillé et al. (2008). Neuronal cultures or cortical slices were harvested in a lysis solution containing $50 \mathrm{~mm}$ Tris- $\mathrm{HCl}$, pH 7.6, 1\% NP-40 (Sigma), 150 mм NaCl, 2 mм EDTA, 1 mм phenylmethylsulfonyl fluoride and Protease and Phosphatase Inhibitor Cocktails (Sigma). Cell lysates were centrifuged $5 \mathrm{~min}$ at 10,000 rpm to isolate the supernatant. Proteins were quantified using the Bradford's protein assay and normalized to $15-20 \mu \mathrm{g}$ of protein per sample. Electrophoresis was performed on $12 \%$ NuPAGE Bis-Tris polyacrylamide gels and gels were transferred to a polyvinylidene difluoride membrane (Polyscreen membrane, PerkinElmer). Membranes were blocked with a solution containing $0.1 \%$ Tween 20 and $200 \mathrm{~mm}$ Tris buffered solution (TTBS) complemented with 5\% nonfat dry milk during $30 \mathrm{~min}$ and incubated with the primary antibody ( $\mathrm{p}$-ERK, 1:200; ERK, 1:1000) at $4^{\circ} \mathrm{C}$ overnight under gentle agitation. Incubation with the secondary peroxidase-conjugated anti-rabbit antibody $(1: 50,000)$ (Sigma) was performed during $2 \mathrm{~h}$ at room temperature. Finally, blots were revealed with an enhanced chemiluminescence Western blotting detection system (Western Lightning Chemiluminescence Reagent Plus, PerkinElmer) and digitally scanned for analysis. The bands corresponding to p-ERK1 and p-ERK2 were pooled for quantifying their intensity, using NIH ImageJ software, version 1.41 for Windows (http://rsb.info.nih.gov.gatel. 
A
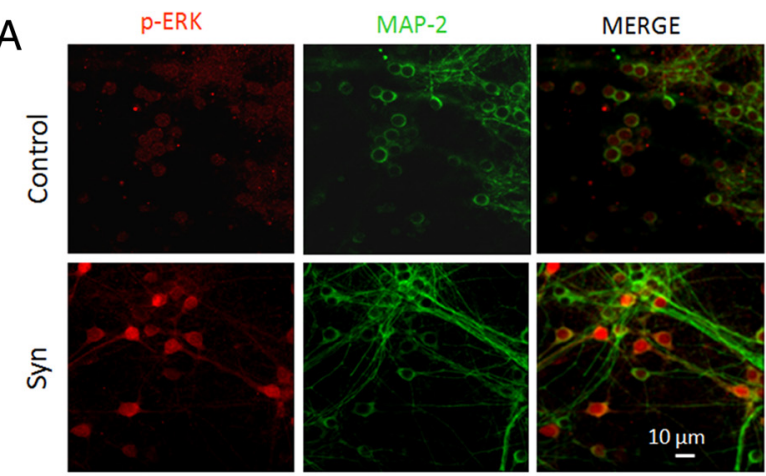

B

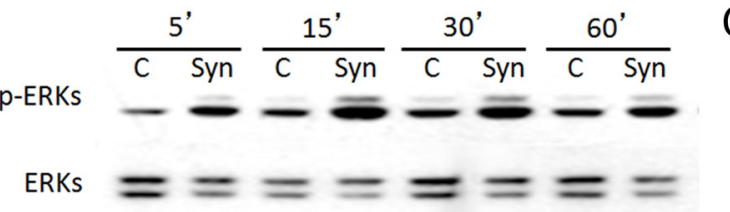

C

\section{p-ERKs}

ERKS

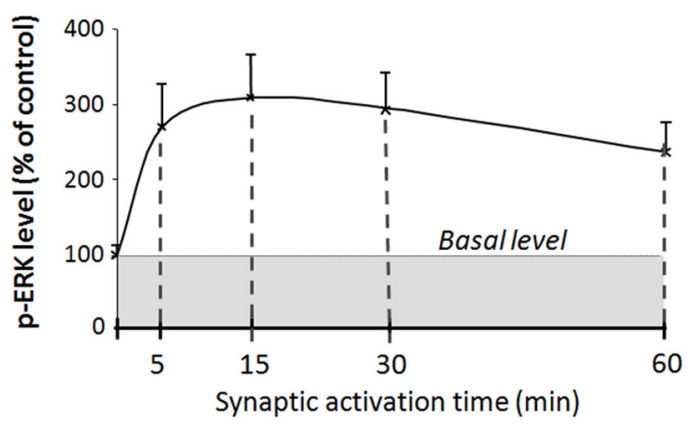

D

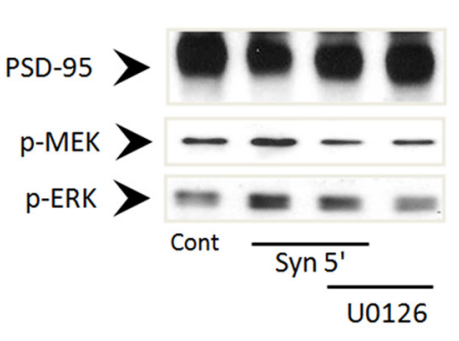

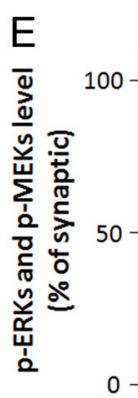

0$$
60
$$

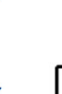

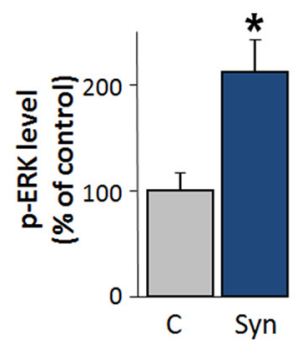

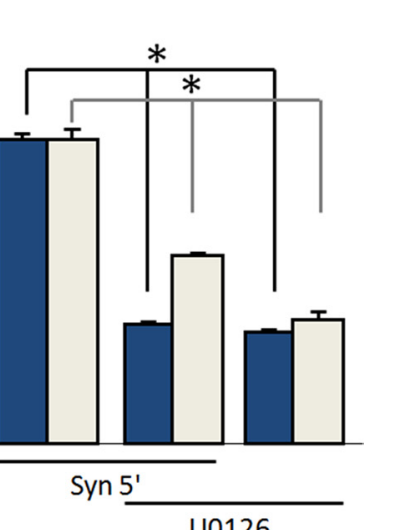

U0126

Figure 1. Bic/4AP application on neurons induces ERK1/2 activation. $\boldsymbol{A}$, Neuronal p-ERKs (red) and MAP-2 (green) immunostaining performed after $30 \mathrm{~min}$ of Bic/4AP (Syn) incubation to drive synaptic activation $(N=3)$. B, Top, Immunoblot of p-ERK1/2 and ERK1/2 extracted from neuronal cultures exposed to Bic/4AP during the indicated times. Bottom, Mean ( $\pm \mathrm{SEM}, N=6$ ) levels of p-ERK1/2 over time quantified from the blots as above and normalized to control (C).C, Top, Immunoblot of p-ERK1/2 on murine adult cortical slices submitted to Bic/4AP (30 min). Bottom, Mean ( \pm SEM, $N=16$ ) levels of $p$-ERK1/2 quantified from blots a above and normalized to control (C). ${ }^{*} p<0.05$, significant difference compared with control. $\boldsymbol{D}$, Immunoblot of PSD-95, p-MEK and $p$-ERK1/2 from extracts of postsynaptic fractions of cortical neurons exposed to $5 \mathrm{~min}$ of Bic/4AP with or without coapplication of MEK inhibitor U0126. E, Mean ( \pm SEM, $N=3$ ) levels of MEK and ERK1/2 phosphorylation quantified from blots as on the left and normalized (100\%) to stimulated condition. Statistical analysis was performed by Kruskal-Wallis test followed by Dunn's post hoc test. ${ }^{*} p<0.05$, significant difference compared with Bic/4AP condition.

inist.fr/ij/), expressed as arbitrary units. To analyze the total ERK content of the samples, blots were incubated in a stripping buffer $(62 \mathrm{~mm}$ Tris $\mathrm{HCl}$; $\%$ SDS; pH 6.8 and $100 \mathrm{~mm} \beta$-mercaptoethanol) for $30 \mathrm{~min}$ at $50^{\circ} \mathrm{C}$. After 3 washes, the same blots were incubated with TTBS containing $5 \%$ nonfat dry milk and probed with an antibody raised against ERKs protein $(1: 1000)$ under the same conditions as described for p-ERK1/2 immunoblots. Data are presented as the mean \pm SEM from at least three different experiments. Because there was no change in the levels of total ERK1 and ERK2, values of phosphorylated ERK1/2 (p-ERK1/2) were normalized to the values of total ERK1 and ERK2.

\section{Immunoprecipitation}

Aliquots $(500 \mu \mathrm{g})$ of PSD fractions were diluted to $500 \mu \mathrm{l}$ with dilution buffer ( $50 \mathrm{~mm}$ Tris $\mathrm{HCl}$, $150 \mathrm{~mm} \mathrm{NaCl}, \mathrm{pH}=7,4)$ and incubated with GluN2B antibody overnight at $4^{\circ} \mathrm{C}$. The following day, they were mixed with $40 \mu$ l of Protein G Dynabeads (Invitrogen) for $1 \mathrm{~h}$. Beads were then washed twice in Buffer A ( 50 mM Tris HCl, 150 mu NaCl, Triton X-100 0,1\%, 1 mm EDTA) and twice with Buffer B (50 mm Tris $\mathrm{HCl}, 300 \mathrm{~mm}$ $\mathrm{NaCl}$, Triton X-100 0,1\%, 1 mm EDTA). Finally proteins were eluted in 10-40 $\mu$ l of loading SDS-PAGE buffer by boiling.

\section{Transfection of cortical neurons}

$\alpha$ and $\beta$ CaMKII shRNAs and $\beta$ CaMKII rescue construct (containing silent point mutations in the sequence recognized by the shRNA) were kindly provided by Dr Y. Hayashi (RIKEN Brain Science Institute, Saitama, Japan) and S. H. Lee, (Medical College of Wisconsin, Milwaukee, Wisconsin) respectively, GCaMP2 by Dr J. Nakai, (RIKEN Brain Science Institute, Saitama, Japan) and the dominant-negative CaMKI by Dr T. Soderling (Oregon Health and Science University, Portland, Oregon). The design of $\alpha$ CaMKII rescue construct was described by Opazo et al. (2010). Cortical neurons (13 DIV) were transfected with GFP, GFP-fusion proteins, and shRNAs using the phosphate-calcium technique, as previously described (Léveillé et al., 2008) or using Lipofectamine 2000 (Invitrogen; Hudmon et al., 2005). Unless mentioned, experiments were performed on 14 DIV cultures.

\section{Live imaging}

Calcium imaging. Calcium imaging with Fura-2 was performed on mouse primary cortical neuron cultures (14 DIV) or transfected HEK-293 following the procedure described by Léveillé et al. (2008). All stimulation protocols were separated by a minimum of 5 min to allow full recovery to the basal level of $\left[\mathrm{Ca}^{2+}\right]_{i}$. Ifenprodi displays much greater inhibition of GluN2Bcontaining NMDARs when it is applied before agonist application (Legendre and Westbrook, 1991; Tovar and Westbrook, 1999). Consequently the GluN2B antagonist was applied for $60 \mathrm{~s}$ to reach equilibrium prior and during agonist applications. Changes in $\left[\mathrm{Ca}^{2+}\right]_{i}$ were determined from the area under the curve (AUC), calculated as the integral on a $2 \mathrm{~min}$ period after the beginning of drug application.

Fluorescence recovery after photobleaching experiments. Fluorescence recovery after photobleaching (FRAP) experiments were performed $1 \mathrm{~d}$ following transfection of neurons with mGFP- $\alpha$ CaMKII. Images were taken with a Nikon Eclipse (TE2000-E) inverted C1 confocal microscope equipped with an oil-immersion Nikon $60 \times$ objective with 1.4 numerical aperture. mGFP- $\alpha$ CaMKII was bleached at $480 \mathrm{~nm}$ and the recovery was measured during $3 \mathrm{~min}$ (100 frames, $1.87 \mathrm{~s} /$ frame). Analysis was performed using Origin software.

Time-lapse imaging. Time-lapse imaging of mCherry-CaMKII translocation was essentially performed as previously described for mGFPCaMKII (Bayer et al., 2006), excepted that GCaMP2 was cotransfected to monitor changes in intracellular $\mathrm{Ca}^{2+}$ induced by synaptic NMDAR activation. For dual color imaging, we used an eGFP/DsRed filter set (Chroma Technology) and sequentially excited GCaMP2 (485 nm 25X 
filter) and mCherry (565 $\mathrm{nm} 25 \times$ filter) with a Lambda DG-4 equipped with a 175W Xenon lamp (Sutter Instrument). GCaMP2 images were acquired every 2-3.5 s with an EMCCD camera (QuantEM:512SC, Photometrics).

We measured CaMKII translocation in spines identified as protrusions with a head localized $<5$ $\mu \mathrm{m}$ from the dendritic shaft to avoid sampling from long filopodia, which might be erroneously included in the sampling of spines. Relative changes in synaptic mCherry-CaMKII fluorescence were calculated by subtracting the integrated intensity in synaptic regions of interest (ROIs) before stimulation $\left(\mathrm{F}_{0}\right)$ from the integrated intensity in the same ROIs during or 15 min after the stimulation (F). The $\Delta \mathrm{F}$ obtained $\left(\mathrm{F}-\mathrm{F}_{0}\right)$ was then divided by the value before the stimulation $\left(\mathrm{F}_{0}\right)$.

Spine volume analysis. Spine volume analysis was performed as described by Pi et al. (2010). Briefly, neurons were cotransfected with mCherry$\alpha$ CaMKII (WT or I205K) and mGFP to quantify spine size. The two signals were separated as described above for mCherry and GCaMP2. We chose only dendritic protrusions that were present on all images (avoiding dynamic filopodialike structures) and removed out-of-focus images. Spine outlines were manually traced for each plane using the mGFP signal and the associated synaptic integrated intensity was measured. Fold increases in spine volume $\left(F / F_{0}\right)$ were calculated by dividing the value during or $15 \mathrm{~min}$ after the stimulation by the mean value before the stimulation.

Time-lapse imaging. Time-lapse imaging of superecliptic pHluorin (SEP)-GluA1 and DsRed-Homer was performed on a Zeiss Axiovert $200 \mathrm{M}$ microscope with a $63 \times, 1.4 \mathrm{NA}$ oil objective. Each minute, a $Z$-stack of 10 images $(0.45 \mu \mathrm{m}$ step, $50-100 \mathrm{~ms}$ integration time per frame) was acquired. A deconvolution was applied on each image and, for each time point, images from the $Z$-stack were summed. Those summed projections were then $X Y$ aligned before data analysis. Clusters of DsRed-Homer were detected using a local threshold algorithm and those with an intensity at least 3 SDs higher than the intensity of a $10-15$ pixel box surrounding the cluster were selected. The position of these DsRed-Homer clusters, considered as synaptic, was then tracked. For each cluster, the size of a region of interest was determined based on morphometric analysis and a box was drawn on each projection image, according to the tracked position, to measure the average intensity in both fluorescence channels.

\section{Image analyses}

Images obtained from live imaging were analyzed with MetaMorph software (Molecular Devices). Analysis for SEP-GluA1 was done with MatLab using custom software. Western blot analyses were performed using ImageJ software.

\section{Statistical analyses}

Statistical analyses were performed using GraphPad Prism version 5.00 for Windows (http://www.graphpad.com) or StatView (Abacus) Dunn's post hoc test.
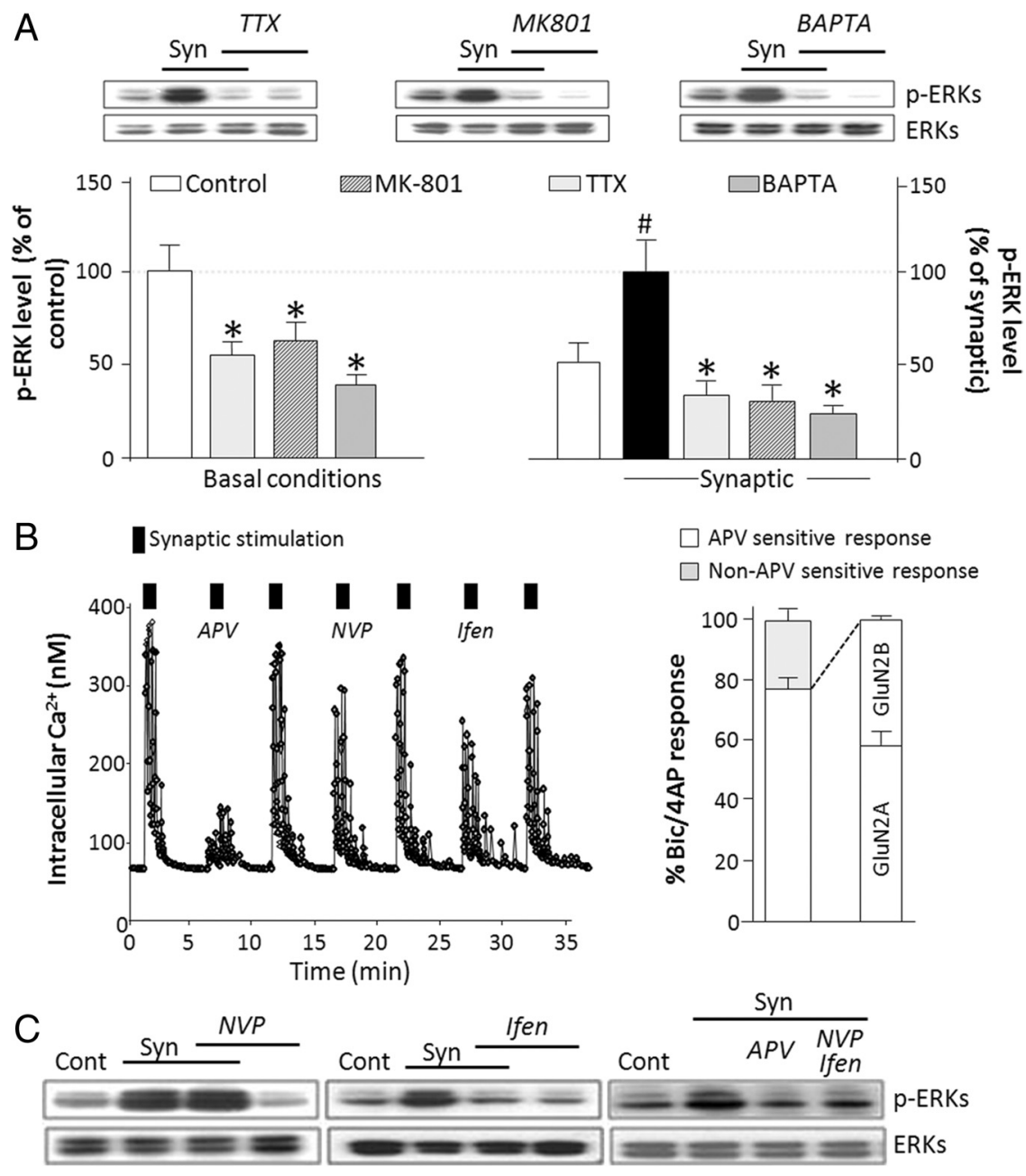

$\square$ Non-APV sensitive response
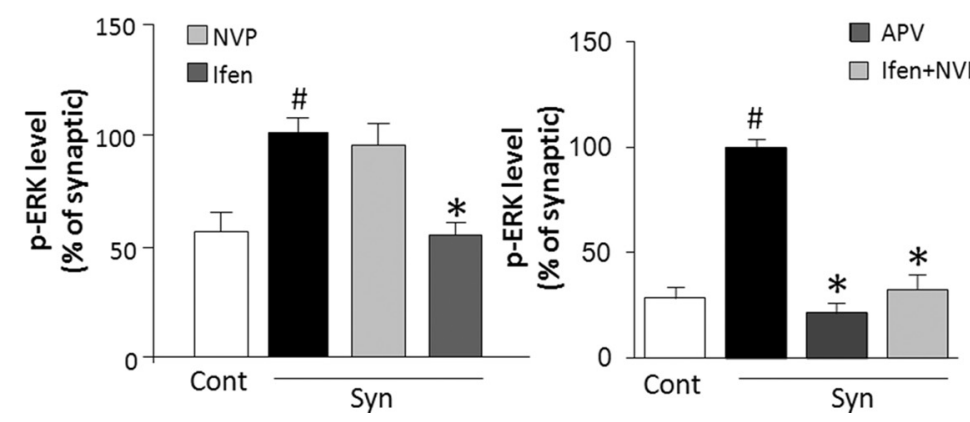

Figure 2. Synaptically induced ERK1/2 phosphorylation involves synaptic GluN1/GluN2B-containing NMDARs. $\boldsymbol{A}$, Top, Immunoblots of $p$-ERK1/2 and ERK1/2 from neurons in basal condition or exposed to Bic/4AP (Syn) for 15 min, in the presence or not of either TTX $(0.5 \mu \mathrm{m})$, MK-801 (10 $\mu \mathrm{m})$ or BAPTA-AM $(20 \mu \mathrm{m})$. Bottom, Mean ( \pm SEM, $N=4)$ levels of p-ERK1/2 and ERK1/2 quantified from blots as above under the indicated conditions and normalized to control (basal conditions, left) or Bic/4AP (synaptic, right). $\boldsymbol{B}$, Left, $\left[\mathrm{Ca}^{2+}\right]_{i}$ was monitored by Fura-2 imaging on neuronal cultures exposed to $30 \mathrm{~s}$ of $\mathrm{Bic} / 4 \mathrm{AP}$, with or without coapplication of NMDAR antagonists (100 $\mu \mathrm{m}$ D-APV; 50 nм NVP-AAM077; $10 \mu \mathrm{m}$ ifenprodil). Right, Mean ( \pm SEM) $\mathrm{Ca}^{2+}$ responses quantified as the area under curve and normalized to synaptic response or $D-A P V$ (open bar)-sensitive response $(N=3$; $n=103$ ). The GluN2A- and GluN2B-sensitive responses were normalized to D-APV-sensitive response. C, Top, Immunoblots of p-ERKs and ERKs extracted from cultures submitted to $15 \mathrm{~min}$ of Bic/4AP (Syn) with or without NVP ( $50 \mathrm{~nm}$ ) or ifenprodil (10 $\mu \mathrm{M})$, APV $(100 \mu \mathrm{m})$ or NVP+Ifen. Bottom, Mean ( \pm SEM, $N=3-4$ ) levels of $\mathrm{p}$-ERK from blots as above, normalized to Bic/4AP without inhibitors. * \# $p<0.05$, significant difference compared with Bic/4AP or control, respectively, after Kruskal-Wallis test followed by or MatLab (The MathWorks Inc.). $N$ represented the number of independent experiments and $n$ the number of regions of interest that were analyzed.

Datasets were tested for normal distribution with Kolmogorov-Smirnoff tests. In cases of normal distribution, ANOVA was performed to test 
A

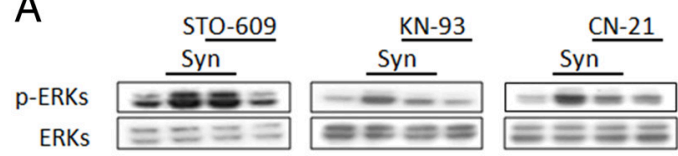

ERKs

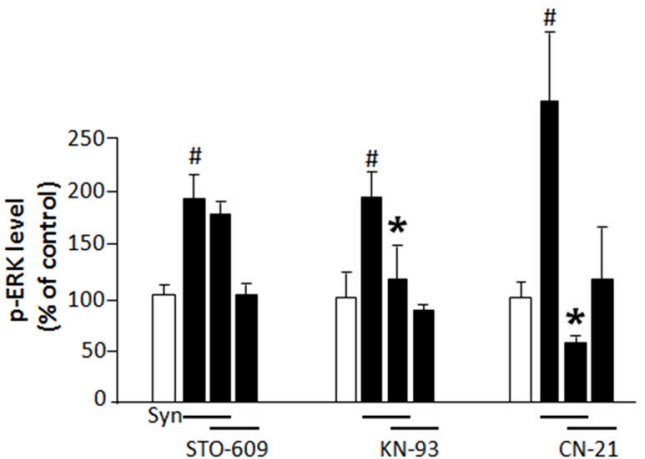

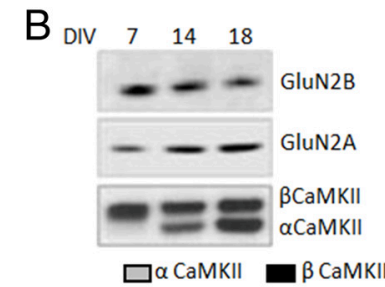
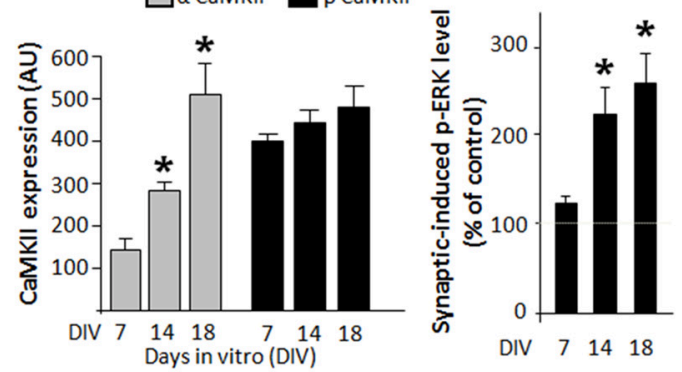

C
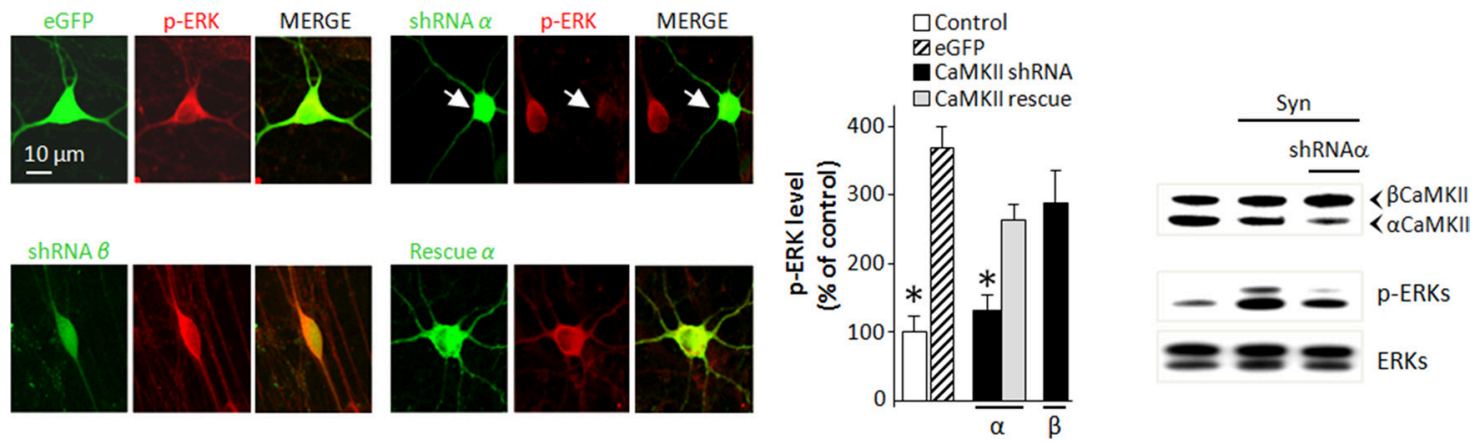

Figure 3. CaMKII is involved in synaptic NMDAR-dependent ERK1/2 activation. $A$, Top, Immunoblots of $p$-ERK1/2 and ERK1/2 from extract of neurons exposed to 30 min of Bic/4AP (Syn), with or without ST0-609 ( $5 \mu \mathrm{M}, \mathrm{N}=7), \mathrm{KN}-93(5 \mu \mathrm{M}, N=5)$ and CN21a ( $5 \mu \mathrm{M}, N=4)$. Bottom, Mean ( \pm SEM, $N=4-6)$ levels of $p$-ERK quantified from blots as above and normalized to control (open bars). Statistical analysis was performed by ANOVA followed by Bonferroni-Dunn's test. * \# $p<0.05$, significant difference compared with Bic/4AP and with control condition, respectively. $\boldsymbol{B}$, Top, Developmental changes of GluN2A, GluN2B and $\alpha / \beta$ CaMKII, as measured by immunoblots from extracts of cortical neurons (DIV 7, 14, or 18) performed with an anti- $\alpha / \beta$ CaMKII, anti-GluN2B and anti-GluN2A. Bottom left, Mean ( \pm SEM, $N=3$ ) levels of $\alpha$ and $\beta$ CaMKIl expression quantified from blots as above. ${ }^{*} p<0.05$, significant difference compared with 7 DIV. Bottom right, Mean $\left( \pm\right.$ SEM,$N=3$ ) $p$-ERK1/2 levels quantified from immunoblots from neuronal cultures of the indicated DIV exposed to $30 \mathrm{~min}$ Bic/4AP and normalized to control (dotted line). ${ }^{*} p<0.05$, significant difference compared with Bic/4AP at 7 DIV. Statistical analysis was performed by ANOVA followed by Bonferroni-Dunn's test. C, Left, Representative images of neurons transfected with GFP \pm $\alpha$ CaMKII shRNA, $\beta$ CaMKII shRNA, or with $\alpha$ CaMKII shRNA + rescue mGFP- $\alpha$ CaMKII, and immunostained for $p$-ERKs (red), after 30 min of Bic/4AP incubation $(N=3 ; n=32-45)$. Middle, Mean ( \pm SEM) levels of $p$-ERK quantified from images as in left and normalized to control. Statistical analysis was performed by ANOVA followed by Bonferroni-Dunn's test. ${ }^{*} p<0.05$, significant difference from the fluorescence intensity of GFP-transfected cells after synaptic activation. Right, Representative immunoblot of CaMKII, $p$-ERK1/2, and ERK1/2 from extracts of cortical cultures infected with a lentiviral $\alpha$ CaMKII shRNA and exposed or not to $30 \mathrm{~min}$ of Bic/4AP (Syn).

for possible differences among groups. Bonferroni correction was used for post hoc comparison. For non-normal distributed datasets, nonparametric tests were applied: Kruskal-Wallis for multiple comparisons and Mann-Whitney's $U$ test with significance correction for double comparisons of independent samples. All measurements are presented as mean \pm SEM. $p>0.05$ was considered as not significant, $p<0.05$ was considered significant $\left.{ }^{*}\right)$.

\section{Results}

Synaptic NMDA receptor activation induces ERK1/2 signaling pathway

NMDARs are mainly found on the postsynaptic membrane of excitatory synapses, but also in extrasynaptic positions (Gladding and Raymond, 2011). To generate a selective activation of synaptic NMDARs, we used stimulation paradigms previously characterized in hippocampal (Hardingham and Bading, 2002) and cortical neurons (Léveillé et al., 2008). As interneurons impose a tonic inhibition in cultured cortical networks, application of bicuculline $(50 \mu \mathrm{M})$ coapplied with $4 \mathrm{AP}(2.5 \mathrm{~mm})$, a weak potassium-channel blocker, induces synchronous bursts of action potentials and strong activation of synaptic NMDARs. We found that after $30 \mathrm{~min}$ of this treatment, $65 \%$ of MAP2-positive neurons displayed an increase in phosphorylated forms of ERK1/2 immunostaining (Fig. 1A). We then determined the temporal profile of ERK1/2 activation by analyzing phosphorylated ERK1/2 and total ERK1/2 at different time points with immunoblotting. Continuous Bic/4AP application induced a rapid and sustained ERK1/2 phosphorylation (from $5 \mathrm{~min}$ to $1 \mathrm{~h}$ ) without altering total ERK1/2 amounts (Fig. $1 \mathrm{~B}$ ). These findings obtained from primary cortical neurons were further confirmed with postnatal day $35-42$ cortical slice preparations, in which a 30 min Bic/4AP treatment induced a marked increase in phosphorylated ERK1/2 (Fig. 1C). These results confirm that ERK signaling is activated by synaptic NMDAR activation (Krapivinsky et al., 2003). Based on our immunocytochemical analysis, this ERK signaling is clearly present in the somatic regions. We then asked whether ERK might also be present and activated in the PSD, and whether the upstream kinase in the pathway [mitogen-activated protein kinase kinase (MEK)] is also there and activated by synaptic NMDAR activation. We isolated PSD fractions from cortical neurons and analyzed p-ERK and p-MEK. As illustrated in 
Figure $1 D$, MEK and ERK were both present in the PSD fraction (validated by the postsynaptic marker PSD-95) and both were phosphorylated within $5 \mathrm{~min}$ of Bic/ 4AP stimulation, but not in the presence of MEK inhibitor, U0126 (Fig. 1D,E). These results suggest that the ERK signaling pathway can be engaged rapidly at the PSD, following synaptic NMDAR activation.

To determine whether $\mathrm{Ca}^{2+}$ influx through synaptic NMDARs is required for ERK1/2 activation, we treated cortical cultures with the selective blocker of $\mathrm{Na}^{+}$channels, TTX $(0.5 \mu \mathrm{M})$, the NMDAR antagonist MK-801 (10 $\mu \mathrm{M})$ or the membrane-permeant $\mathrm{Ca}^{2+}$ chelator BAPTA-AM (20 $\mu \mathrm{M}, 30 \mathrm{~min}$ prior) during synaptic NMDAR activation. Under these three conditions, ERK1/2 phosphorylation was fully blocked, confirming a $\mathrm{Ca}^{2+}$ and NMDAR-dependent control of ERK1/2 activation in cortical neurons (Fig. 2A).

\section{Role of synaptic NMDAR-specific subunit composition in \\ ERK1/2 signaling}

The distinct involvements of GluN2A and GluN2B in NMDAR-dependent signaling and plasticity have been the focus of many studies (Liu et al., 2004; Massey et al., 2004; Barria and Malinow, 2005; Zhao et al., 2005; Fox et al., 2006; Izumi et al., 2006). We therefore aimed at determining their specific role in NMDAR-dependent ERK1/2 signaling by using subunit-specific antagonists: ifenprodil (GluN2B) and NVP-AAM077 (GluN2A). To determine the adequate protocol of application and the optimal concentration of these inhibitors for effective and specific inhibition, we transfected GluN1/GluN2A and GluN1/GluN2B separately in HEK-293 cells. We then assayed the sensitivity of these receptors to increasing doses of the inhibitors using NMDA application and by measuring the intracellular $\mathrm{Ca}^{2+}$ concentration $\left(\left[\mathrm{Ca}^{2+}\right]_{\mathrm{i}}\right.$ ) (data not shown). Ifenprodil displayed an $\mathrm{IC}_{50}$ of 191 nM for GluN1/GluN2B. NVP-AAM077 IC $_{50}$ values differed by approximately sixfold between the two receptor subtypes $\left(\mathrm{IC}_{50}=14\right.$ nM for GluN1/GluN2A versus $91 \mathrm{~nm}$ for GluN1/GluN2B). Thus, for NVP-AAM077, we used $0.05 \mu \mathrm{M}$ for subsequent experiments, as $>80 \%$ of GluN2A-containing NMDARs were blocked, with only a negligible attenuation of GluN1/GluN2B response observed (data not shown; Neyton and Paoletti, 2006).

Next, we used these two inhibitors to assess the involvement of GluN2A and GluN2B-containing NMDARs on Bic/4AP-induced changes in $\left[\mathrm{Ca}^{2+}\right]_{\mathrm{i}}$. D-APV, an NMDAR competitive antagonist $(100 \mu \mathrm{M})$ induced an $80 \%$ inhibition of the $\left[\mathrm{Ca}^{2+}\right]_{\mathrm{i}}$ increase induced by $30 \mathrm{~s}$ Bic/4AP application (Fig. $2 \mathrm{~B}$ ). NVP-AAM077 $(0.05 \mu \mathrm{M})$ blocked $48 \%$ of the Bic/4AP-induced $\left[\mathrm{Ca}^{2+}\right]_{\mathrm{i}}$ increase, while ifenprodil $(10 \mu \mathrm{M})$ blocked $32 \%$ (Fig. $2 B$ ). The combina-
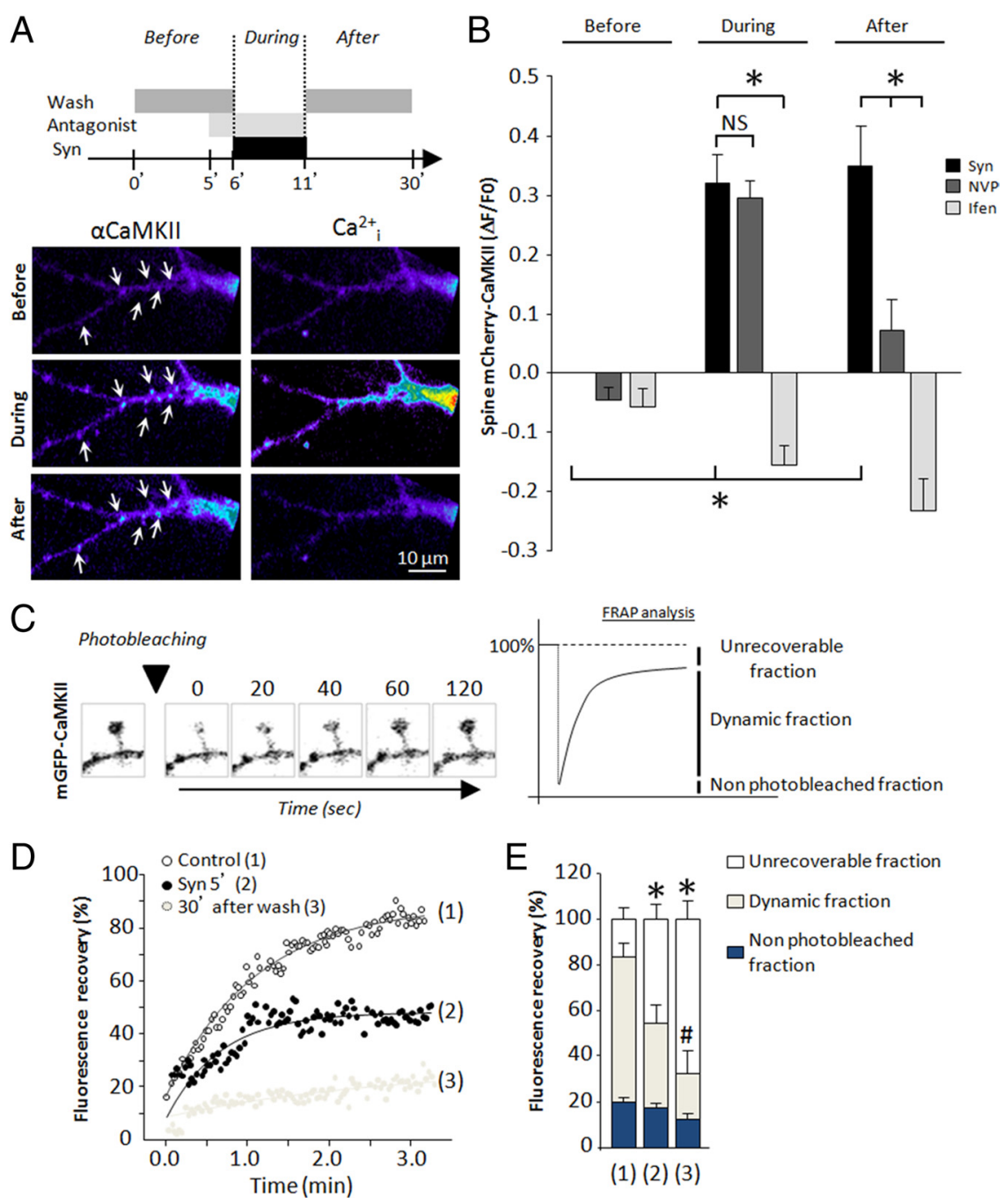

Figure 4. $\quad \alpha$ CaMKII is enriched and locked in dendritic spines after synaptic NMDAR activation. $\boldsymbol{A}$, Representative images of a dendrite segment from a neuron cotransfected with mCherry- $\alpha$ CaMKII and GCaMP2 before, during, and after $5 \mathrm{~min}$ of Bic/4AP stimulation (black bar on top diagram). $\alpha$ CaMKII translocates to synaptic sites of higher $\mathrm{Ca}^{2+}$ concentrations (see arrows). $\boldsymbol{B}$

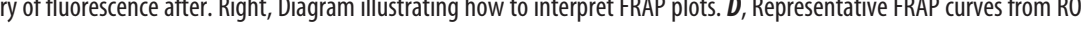
followed by Bonferroni-Dunn's test. ${ }^{*},{ }^{*} p<0.05$, significant difference compared with the percentage of stable or dynamic fraction, respectively, in control condition.

tion of both NVP-AAM077 and ifenprodil blocked $82.4 \pm 1.4 \%$ ( $N=2, n=36$, data not shown) of the increase. Our interpretation from these inhibitor responses is that both receptor subtypes contribute significantly to the APV-sensitive increase in $\left[\mathrm{Ca}^{2+}\right]_{\mathrm{i}}$, though GluN2A-containing receptors appeared to contribute slightly more (60\% for GluN2A versus $40 \%$ for GluN2B). To examine the involvement of GluN2A and GluN2B subunits in synaptic NMDAR-induced ERK1/2 activation, cultures were incubated for 15 or $60 \mathrm{~min}$ in Bic/4AP with or without ifenprodil or/and NVP-AAM077. Remarkably, we observed that while ifenprodil fully blocked the ERK1/2 activation, NVP-AAM077 had no effect (Fig. $2 C$ ). These results argue that GluN2B-containing NMDAR activation, but not GluN2A, leads to ERK1/2 phosphorylation, upon Bic/4AP stimulation. Furthermore, they suggest 
A

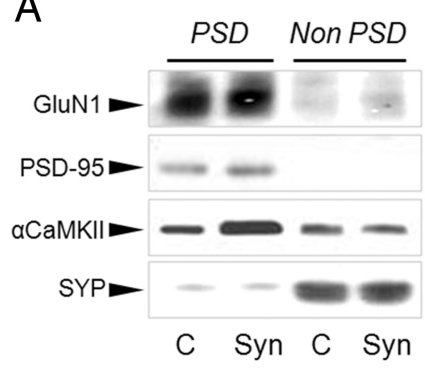

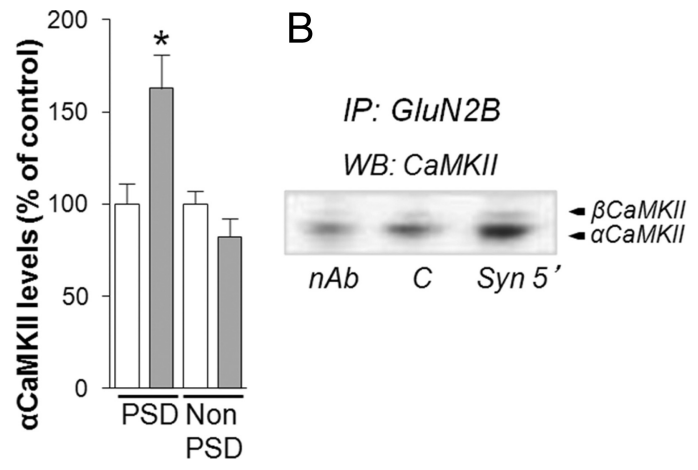

Figure 5. $\alpha$ CaMKII binds GluN2B subunit in PSD fraction after synaptic NMDAR activation. $\boldsymbol{A}$, Left, Immunoblots of PSD fractions harvested from cortical neurons exposed to $5 \mathrm{~min}$ Bic/4AP (Syn) or control (C). Right, Mean ( \pm SEM) levels of $\alpha$ CaMKII in the indicated fractions from control (open bars) or Bic/4AP-treated cultures ( 5 min, gray bars). $\alpha$ CaMKII is significantly more recruited at the PSD after synaptic activation compared with control $\left({ }^{*} p<0.05\right.$, two-tailed MannWhitney test). $B$, Immunoprecipitation of GluN2B, extracted from cortical neurons treated or not (C) with Bic/4AP (Syn) during $5 \mathrm{~min}$, with an anti-GluN2B antibody (nAb indicates IP without GluN2B antibody). Precipitated materials were separated by SDS-PAGE and incubated with $\alpha / \beta$ CaMKII antibody. The blot is representative of three independent experiments and shows an increase of $\alpha$ CaMKII/GluN2B interaction after synaptic activation.

that the source, rather than the amount, of $\mathrm{Ca}^{2+}$ influx dictates ERK1/2 phosphorylation. Because GluN2B and GluN2A have different cytoplasmic tails, likely involving distinct signaling processes, the next logical step for understanding the link with ERK1/2 phosphorylation was to examine a signaling protein associated with $\mathrm{Ca}^{2+}$ and the C-tail of GluN2B.

\section{CaMKII activation mediates synaptic NMDAR-induced ERK1/2 phosphorylation}

Since CaMK pathways have been linked to the MAPK pathway (Chandler et al., 2001; Schmitt et al., 2004), we examined the potential roles of CaMKK (CaMK kinase), CaMKI, CaMKII and CaMKIV, using various inhibitors and dominant-negative mutants of these enzymes. Treatment with the CaMKK inhibitor STO-609 (10 $\mu \mathrm{M}, 30 \mathrm{~min}$ prior and during Bic/4AP application), did not reduce ERK1/2 phosphorylation in cortical neurons (Fig. $3 A$ ), suggesting that CaMKI and IV are not involved. Similarly the cDNA encoding for a dominant-negative CaMKI transfected $48 \mathrm{~h}$ before the experiment did not decrease ERK1/2 phosphorylation (data not shown) confirming that CaMKI is not involved. By contrast, treatment with the CaMKII inhibitor KN-93 (5 $\mu \mathrm{M}$, $30 \mathrm{~min}$ prior and during Bic/4AP application), significantly blocked ERK1/2 phosphorylation (Fig. 3A). Because KN-93 may interfere with other CaMKs or with $\mathrm{Ca}^{2+}$ influx (Wayman et al., 2008), we also used the CaMKII inhibitor peptide CN21a (corresponding to amino acids 43-63 of the endogenous CaMKII inhibitor protein), that potently inhibits CaMKII but not CaMKI or CaMKIV (Vest et al., 2007). Application of the TAT-CN21a inhibited the stimulus-induced increase in ERK1/2 phosphorylation (Fig. 3A). These results suggest that CaMKII mediates the synaptic NMDAR-dependent activation of the ERK1/2 pathway.

\section{$\alpha$ CaMKII promotes ERK1/2 activation}

CaMKII isoforms ( $\alpha$ and $\beta$ ) are differentially expressed in the developing cortex (Lin and Redmond, 2008). In these cortical cultures, $\beta$ CaMKII levels remain developmentally stable, whereas $\alpha$ CaMKII expression increases significantly between 7 and 18 DIV (Fig. 3B). If the total amount or ratio of CaMKII subunit expression is to impact on NMDAR-dependent ERK1/2 signaling, we might expect a concomitant developmental change in ERK1/2 phosphorylation. We thus compared the level of phosphorylated ERK1/2 after synaptic activation in cortical neurons at 7,14 and 18 DIV. Synaptic NMDAR activation induced a significantly higher ERK1/2 phosphorylation at 14 and 18 DIV cortical cultures, compared with 7 DIV. Interestingly, this change in ERK1/2 phosphorylation correlated with a change in $\alpha$ CaMKII levels (Fig. 3B). On the other hand, it inversely correlated with the ratio of GluN2B/GluN2A (Fig. 3B; Bellone and Nicoll, 2007). However, the most important factor in this developmental regulation of ERK1/2 is likely their synaptic development (Tolias et al., 2011). Therefore, to address more directly the possible role of CaMKII subunits on Bic/ 4AP-induced ERK1/2 phosphorylation, we transfected cortical neurons with $\alpha$ CaMKII or $\beta$ CaMKII shRNAs (together with GFP). The selectivity and the efficiency of shRNAs for $\alpha$ CaMKII (Opazo et al., 2010) and $\beta$ CaMKII (Okamoto et al., 2007) was verified previously, and confirmed in our hands (data not shown). We found that only $\alpha$ CaMKII shRNAs interfered with ERK1/2 phosphorylation, which was rescued by the transfection of mGFP- $\alpha$ CaMKII mutant (Opazo et al., 2010) resistant to shRNA silencing (Fig. 3C, left). To confirm the role of $\alpha \mathrm{CaMKII}$, we also used lentiviral transduction particle to knock down $\alpha$ CaMKII expression in a larger proportion of neurons and perform ERK1/2 phosphorylation assay via immunoblotting. As shown in Figure $3 D$ (right), shRNA significantly knocked-down $\alpha$ CaMKII expression, without affecting $\beta$ CaMKII levels, and inhibited synaptic NMDAR-induced ERK1/2 activation. Together, these data demonstrate the key role of $\alpha$ CaMKII in synaptic NMDARinduced ERK1/2 activation.

\section{GluN2B-containing receptors favor the postsynaptic recruitment and retention of $\alpha$ CaMKII}

Previous studies have shown that CaMKII translocates to postsynaptic sites following NMDAR activation (Shen and Meyer, 1999; Bayer et al., 2001, 2006; Otmakhov et al., 2004; Hudmon et al., 2005). Although both GluN2B and GluN2A-containing receptors contribute significantly to synaptically induced $\mathrm{Ca}^{2+}$ increase (Fig. $2 \mathrm{~B}$ ), GluN2B appears to be the main subunit that binds CaMKII in the PSD (Strack and Colbran, 1998; Leonard et al., 1999). However, it is not known whether the selective activity of GluN2B-containing receptors, per se, favors the postsynaptic translocation of CaMKII. We performed time-lapse imaging of mCherry- $\alpha$ CaMKII and GCaMP2, a genetically encoded sensor of free $\mathrm{Ca}^{2+}$ on cortical neurons, during synaptic NMDAR activation with or without GluN2A (NVPAAM077) or GluN2B (ifenprodil) antagonists. Following synaptic activation, cortical neurons displayed an increase of intracellular $\mathrm{Ca}^{2+}$ and an activity-dependent translocation of $\alpha$ CaMKII from dendritic shaft to spines (Fig. 4A). The spine enrichment of mCherry- $\alpha$ CaMKII was maintained $30 \mathrm{~min}$ after a $5 \mathrm{~min}$ short stimulation, whereas the intracellular $\mathrm{Ca}^{2+}$ returned to baseline. Interestingly, $\alpha$ CaMKII translocation was blocked by ifenprodil application, but not by NVP (Fig. 4B). The apparent retention of fluorescent $\alpha$ CaMKII at postsynaptic sites could conceivably be explained by changes in spine volume. To address directly whether the enzyme was retained in spines after stimulation, we used a FRAP assay on mGFP- $\alpha$ CaMKII in single spines at 14 DIV (Fig. $4 C$ ). This FRAP analysis indicated that during and after synaptic activity, mGFP- $\alpha$ CaMKII recovered more slowly compared with basal 
condition (Fig. 4D,E). Furthermore, the fluorescence recovery was less complete following synaptic activation, indicating that a population of $\alpha$ CaMKII remains tightly bound inside the spine (Fig. $4 E$ ). To confirm these data biochemically, we proceeded to a fractionation of cortical neurons exposed to synaptic NMDAR activation to separate PSD and non-PSD fractions. During synaptic activation, the PSD fraction indeed displayed an increase in $\alpha$ CaMKII protein (Fig. 5A). We confirmed by immunoprecipitation assay that GluN2B was an important binding partner for $\alpha$ CaMKII in the spine head upon synaptic activity (Fig. 5B).

Together, these results reveal that GluN2B-containing NMDAR activation induces a robust $\alpha$ CaMKII synaptic translocation and long-lasting retention into the spine, which is likely supported by an interaction with GluN2B (Bayer et al., 2006).

Role of $\alpha$ CaMKII recruitment to synaptic GluN2B-containing NMDARs in ERK1/2 phosphorylation

We next tested the hypothesis that the longlasting interaction between GluN2B and CaMKII is responsible for the synaptic activation-induced ERK1/2 phosphorylation. To this end, we transfected neurons with an $\alpha$ CaMKII mutant (mGFP- $\alpha$ CaMKII I205K) unable to bind GluN2B (Bayer et al., 2006). Overexpression of this mutant was shown to have dominant-negative effects on CaMKII-mediated plasticity when transfected in cultured neurons (Opazo et al., 2010). We found that Bic/ 4AP stimulation did not induce ERK1/2 phosphorylation in neurons transfected with mGFP- $\alpha$ CaMKII I205K, whereas it did in neurons transfected with mGFP$\alpha$ CaMKII (Fig. 6A). These results are consistent with a role for the interaction between GluN2B and $\alpha$ CaMKII in the activation of ERK1/2 pathway occurring upon synaptic NMDAR activation.

If the long-lasting interaction between $\alpha$ CaMKII and GluN2B, following synaptic NMDAR activation, is indeed involved in ERK1/2 phosphorylation, we would predict that the latter should also exhibit a long-lasting kinetic. We showed in Figure 4 that a brief ( $5 \mathrm{~min}$ ) Bic/4AP stimulation can elicit long-lasting retention of $\alpha \mathrm{CaMKII}$ in spines, despite the return of $\mathrm{Ca}^{2+}$ to baseline. We thus repeated this protocol and found that ERK1/2 phosphorylation levels remained elevated for at least $30 \mathrm{~min}$ after stimulation (Fig. 6B).

Altogether, these results strongly suggest that long-lasting ERK1/2 phosphorylation is supported by the long-lasting $\alpha$ CaMKII-GluN2B interaction that occurs at synapses following strong synaptic stimulation. We therefore set out to examine how such interaction controls ERK1/2-dependent plasticity.
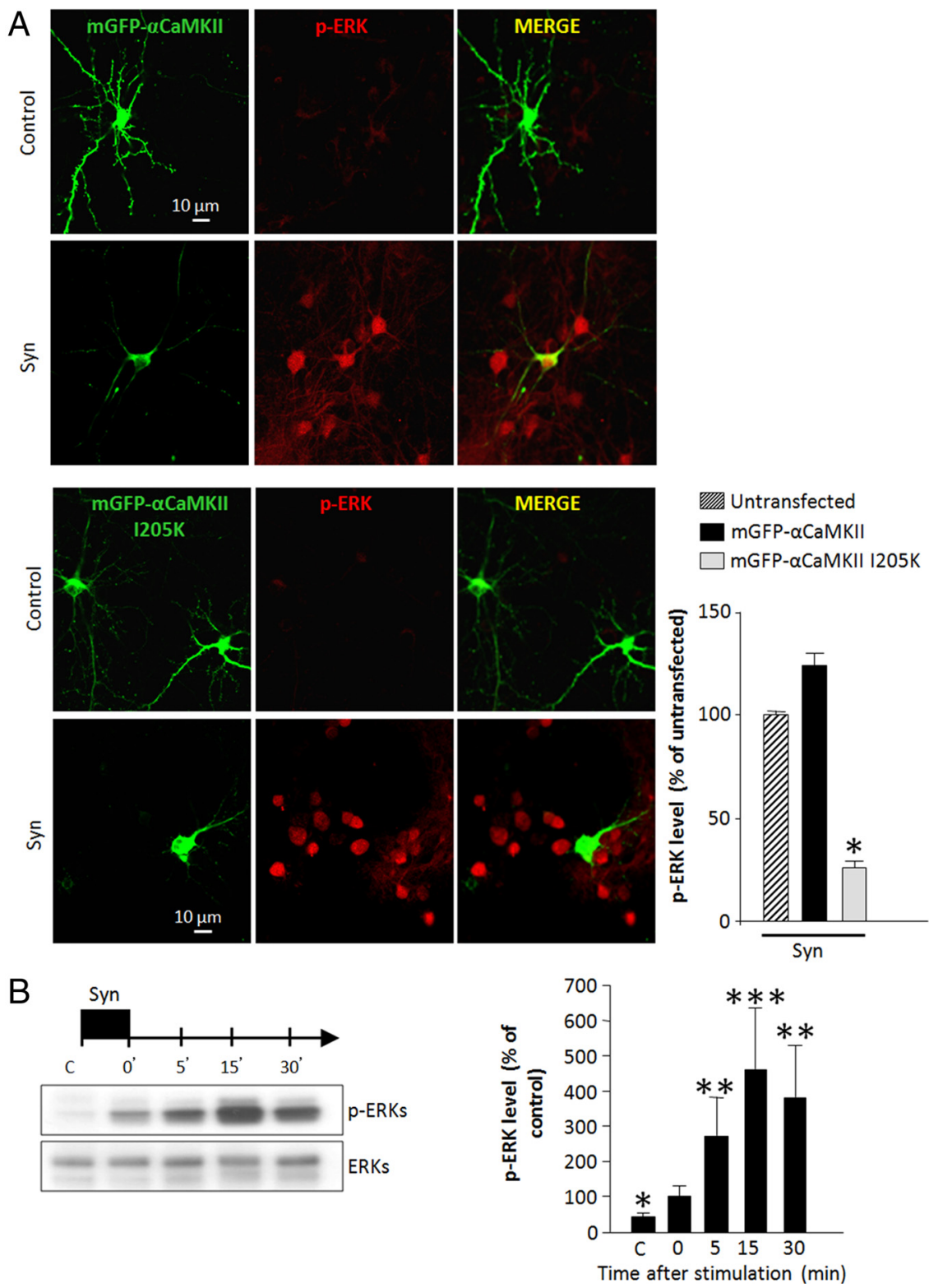

Figure 6. $\alpha$ CaMKII and GluN2B interaction is necessary for synaptically induced ERK1/2 activation. $\boldsymbol{A}$, Left, $\mathrm{p}$-ERK1/2 immuno staining (red) on cortical neurons transfected with cDNA encoding for mGFP- $\alpha$ CaMKII or mGFP-CaMKII I205K and treated for 30 min with $\operatorname{Bic} / 4 A P(N=3-5)$. Right, The histogram represents the mean ( \pm SEM) p-ERK1/2 fluorescence intensity quantified from images as shown for the indicated conditions and normalized to the untransfected condition, control $(n=15 ; N=4)$ or I205K mutant $(n=39 ; \mathrm{N}=5)$. ${ }^{*} p<0.05$, significant difference compared with untransfected neurons. $\boldsymbol{B}$, Left, Immunoblots of P-ERK1/2 and ERK1/2 from extracts of cortical neurons exposed to 5 min synaptic activation and harvested at the indicated times of washing. Right, Mean ( \pm SEM, $N=6$ ) levels of $p$-ERK quantified from blots as in left and normalized (100\%) to the value immediately after stimulation. ${ }^{* *} p<0.01,{ }^{* * *} p<0.001$, significant difference compared with the value obtained immediately after stimulation. Statistical analysis was performed by ANOVA followed by Bonferroni-Dunn's test.

\section{Role of CaMKII/GluN2B complex in ERK-mediated plasticity} Dendritic spines are highly dynamic structures, and their activity-induced rapid remodeling has been often correlated with functional plasticity. Because interfering with ERK1/2 signaling has been shown to also interfere with the induction of LTP (English and Sweatt, 1996; Zhu et al., 2002), including in cortical slices (Di Cristo et al., 2001), possibly by contributing to spine remodeling and AMPAR recruitment (Sweatt, 2001; Thomas and Huganir, 2004; Patterson et al., 2010), we determined whether the NMDAR subunit composition and the interaction between GluN2B and $\alpha$ CaMKII regulate the activity-driven spine enlargement and AMPAR synaptic accumulation. 
A

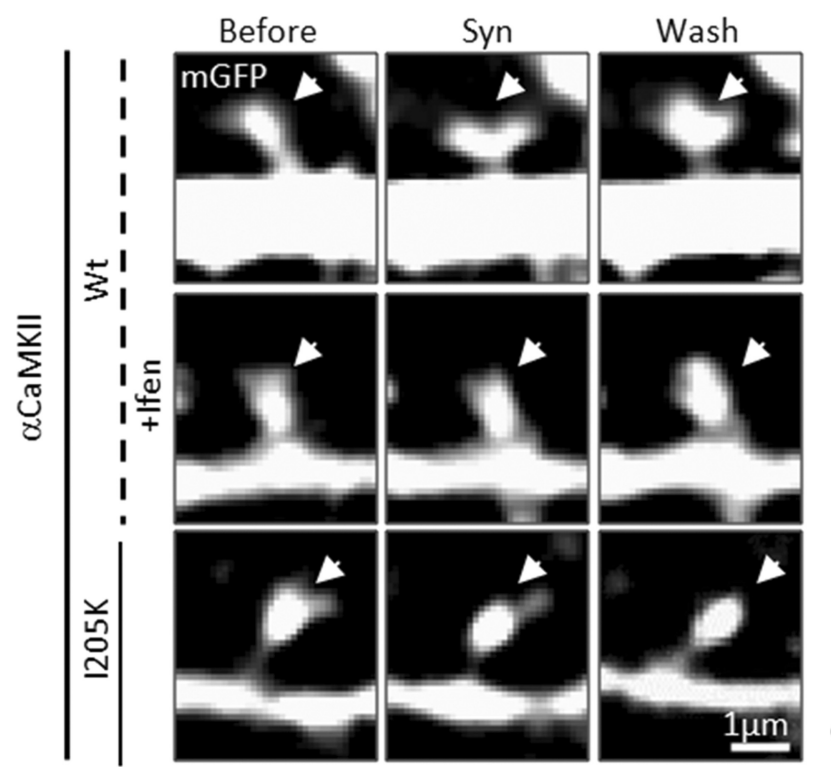

B
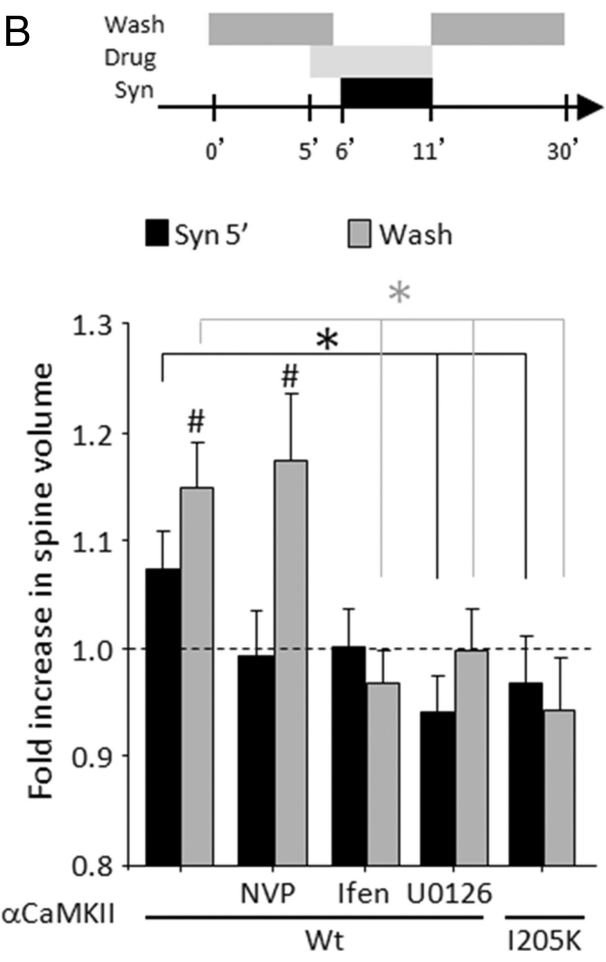

Figure 7. CaMKII/GluN2B complex and ERK regulate synaptic NMDAR-dependent structural plasticity. A, Images of spines from cortical neurons transfected with CDNA encoding for mCherry$\alpha$ CaMKII or mCherry- $\alpha$ CaMKII I205K, together with mGFP and exposed to $5 \mathrm{~min}$ Bic/4AP (Syn) in the presence or not of GluN2 antagonists (NVP, Ifen) or ERK inhibitor (U0126). Spine volume changes were followed before, during, and after synaptic activation. $B$, Mean ( \pm SEM; $N=5-9, n=35-72$ spines) fold increase in spine volume normalized to before the stimulation (dotted lines). Statistical analyses were performed using the Wilcoxon rank sum test in MatLab (The MathWorks Inc.). ${ }^{*} p<0.05$ compared with the spine volume before stimulation; ${ }^{*} p<0.05$, significant difference compared with the spine volume after stimulation in control condition. Statistical analysis was performed by repeated-measures ANOVA followed by Bonferroni-Dunn's test.

To investigate the role of NMDAR subunit composition in spine volume alterations during and after synaptic activation, we transfected neurons with a cDNA encoding for mCherry$\alpha$ CaMKII together with mGFP to visualize the neuronal morphological changes. We found that synaptic activation was accompanied by an increase in spine volume $(\sim 15-20 \%)$ that was maintained $20 \mathrm{~min}$ after synaptic activation (Fig. 7A). This change of spine volume was fully blocked by ifenprodil $(10 \mu \mathrm{M})$ and U0126 (1 nM), but not by NVP, consistent with a GluN2BERK-dependent process. Furthermore, replacement of mCherry$\alpha$ CaMKII by mutated mCherry- $\alpha$ CaMKII I205K prevented the spine remodeling, consistent with a process requiring GluN2BCaMKII interaction (Fig. $7 A, B$ ). To measure synaptic insertion of GluA1-containing AMPARs, we expressed SEP fused to the N terminus of the GluA1 subunit of AMPARs (SEP-GluA1) in the neurons and used live imaging to monitor SEP-GluA1 surface expression (Opazo et al., 2010). We found that 5 min synaptic activation resulted in a marked increase in SEP-GluA1 fluorescence in many dendritic spines (Fig. $8 A$ ). We quantified the integrated intensity change of SEP-GluA1 fluorescence at synapses before, during and after Bic/4AP stimulation and found that synaptic NMDAR activity resulted in a significant increase in synaptic insertion of GluA1-containing AMPARs. As seen for spine remodeling, we observed that the increase in SEP-GluA1 signal at synapses was fully blocked by ifenprodil and U0126, but not by NVP, and we found that overexpression of CaMKII I205K prevented synaptically induced SEP-GluA1 recruitment (Fig. $8 B, C$ ). These data argue that ERK1/2-dependent synaptic plasticity is dependent on GluN2B activity and interaction with CaMKII.

\section{Discussion}

Sustained ERK1/2 activation plays a key role in the long term potentiation of synaptic transmission (Sweatt, 2004, 2009; Thomas and Huganir, 2004). One of the signaling events that activates ERK1/2 cascade is a transient rise in cytosolic $\mathrm{Ca}^{2+}$ caused by NMDAR activation (Wang et al., 2004). In this study, we further dissected the route between the activation of synaptic NMDAR and the downstream ERK1/2 signaling pathway. We have provided evidence that GluN2B activation, CaMKII activity and the association between $\alpha$ CaMKII and GluN2B are important in this pathway ERK1/2 activation. We showed that interfering with GluN2B activation, CaMKII binding to GluN2B and ERK1/2 activation all impeded on the activity-dependent recruitment of synaptic AMPARs and spine growth.

GluN2A and GluN2B are the predominant subunits in cortical neurons and confer distinct physiological and molecular properties to NMDARs. As an illustration, we showed that GluN2B (but not GluN2A)-containing NMDAR activation leads to ERK1/2 phosphorylation. Although $\mathrm{Ca}^{2+}$ is a key determinant in ERK1/2 activation, the level of increase in cytosolic $\mathrm{Ca}^{2+}$, after synaptic NMDAR activation, is not sufficient to explain this activation. Indeed, our pharmacological analysis of the contribution of GluN2A- versus GluN2B-containing receptors in raising cytosolic $\mathrm{Ca}^{2+}$, which was consistent with previous studies (Kirson and Yaari, 1996; Sobczyk et al., 2005; Thomas et al., 2006; Harris and Pettit, 2008), did not point to a causal relationship between $\mathrm{Ca}^{2+}$ levels and the differential effects that the GluN2 subunit-specific inhibitors had on ERK1/2 phosphorylation. Although, local $\mathrm{Ca}^{2+}$ levels in the vicinity of the NMDAR might be 
differentially affected by selectively blocking one subunit or the other, it is likely that something else distinguishing GluN2B from GluN2A is involved in selectively mediating ERK1/2 activation. However, other studies, using different models and/or different assays, have obtained results that are not immediately consistent with our observations, suggesting instead a link between GluN2A and ERK1/2 (Kim et al., 2005; Jin and Feig, 2010). On the other hand, the specific link between GluN2B and ERK1/2 activation has been proposed in other studies (Krapivinsky et al., 2003; Chen et al., 2007). The reasons behind these possible discrepancies are unclear. Other than the experimental conditions, the circuit under study and the assays performed, one feature that is likely significant is the developmental stage of the circuit. The rodent $14-18$ DIV cortical cultures are representative of a developing circuit model, a period during which the role of GluN2B may be more toward promoting LTP (Yoshimura et al., 2003) while the prevalence of GluN2A toward LTP induction may be more significant in more mature circuits (Kim et al., 2005; Jin and Feig, 2010). Since ERK1/2 activation and LTP induction are linked (English and Sweatt, 1997; Di Cristo et al., 2001; Zhu et al., 2002), we might expect that the GluN2A/2B to ERK1/2 activation is also developmentally regulated. An important study that helped in teasing out the distinct roles of GluN2B and GluN2A in the signaling of LTP is from Foster et al. (2010), which showed, by exchanging the cytoplasmic tails of each subunit, that the one of GluN2B is playing a critical role in LTP. Meanwhile, the increased ratio of GluN2A/GluN2B, later in development, may confer a more important role for GluN2A in gating the postsynaptic $\mathrm{Ca}^{2+}$ necessary for LTP. Interestingly, knocking out GluN2B later in development appeared to have a lesser impact on LTP (von Engelhardt et al., 2008). Given the key role of ERK1/2 signaling in the induction of LTP, our observation of a GluN2B-specific induction of ERK1/2 phosphorylation in cortical cultures is consistent with a preferred role for GluN2B-containing NMDARs in LTP in developing circuits (Barria and Malinow, 2005). Finally, it should be acknowledged that the role of ERK1/2 in early LTP is also not universal (Winder et al., 1999; Steward et al., 2007). Again, the signaling processes that regulate long-term forms of plasticity are often distinct across circuits, developmental stages and induction protocols.

Several members of the CaMK family have been proposed to transduce elevated intracellular $\mathrm{Ca}^{2+}$ into ERK1/2 activation (Agell et al., 2002; Schmitt et al., 2004). However, because of its ability to interact with C-terminal domain of GluN2B (Gardoni et al., 1998; Strack and Colbran, 1998; Bayer et al., 2001, 2006),

A
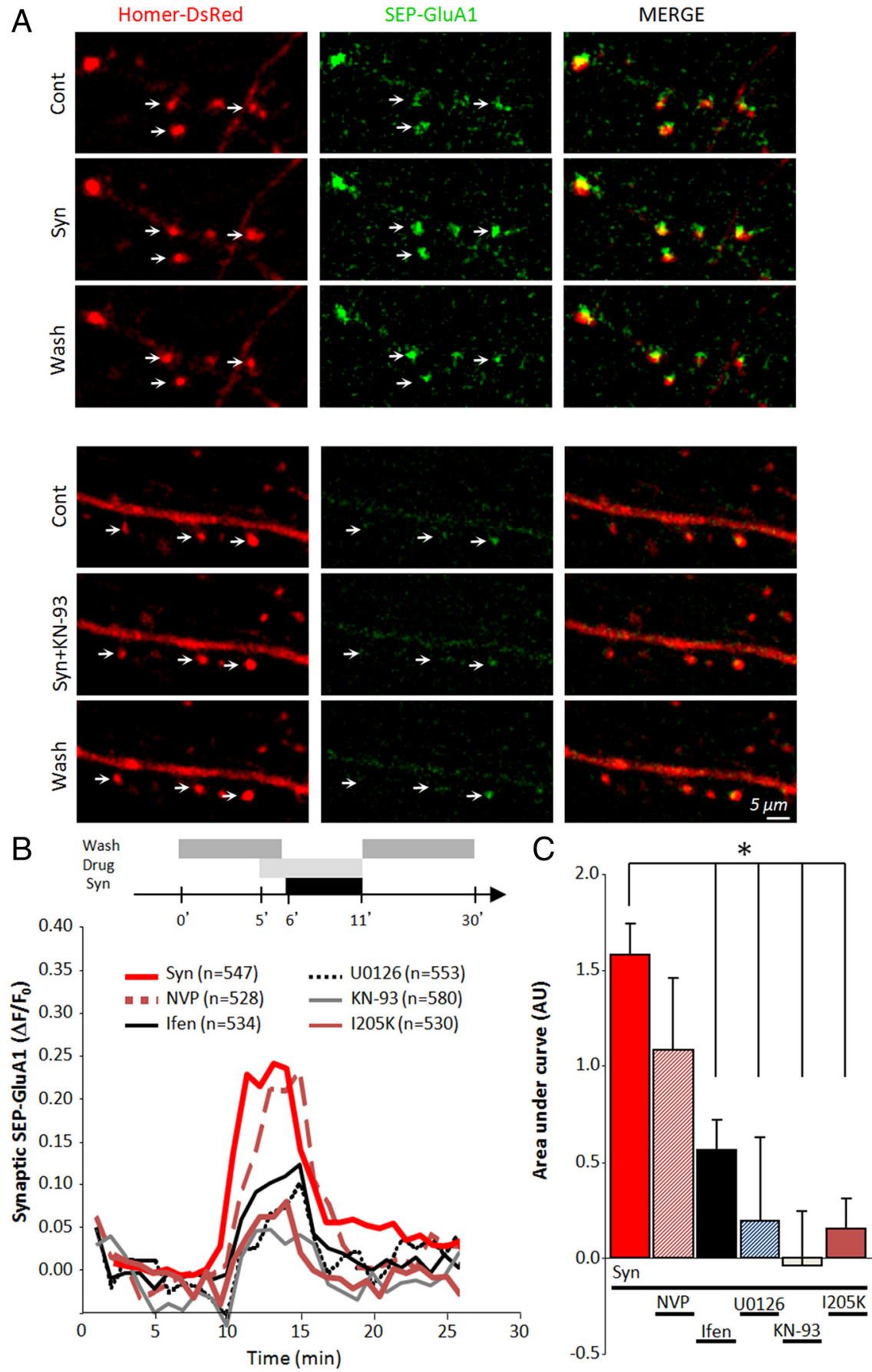

Figure 8. CaMKII/GluN2B complex and ERK regulate synaptic NMDAR-dependent recruitment of AMPARs. $A$, Time lapse images of cortical neurons transfected with Homer-DsRed and SEP-GluA1, before (Cont), after 5 min Bic/4AP (Syn \pm KN93), and after 20 min of wash. $\boldsymbol{B}$, Mean $\Delta F / F_{0}$ synaptic SEP-GluA1 over time measured at all Homer-DsRed-positive synapses from images as in $\boldsymbol{A}$ ( $N=6 ; n=530-550$ synapses). The fluorescence was normalized to the mean of 16 reference images acquired before stimulation. ${ }^{*} p<0.05$, significant difference compared with Bic/AP-treated neurons without inhibitors. C, Mean ( \pm SEM) levels of increase in synaptic SEP-GluA1 determined by the area under each curve, between 8 and $21 \mathrm{~min}$, on the graph in $\boldsymbol{B}$. Significance between conditions was assessed by two-way ANOVA followed by a protected least significant difference Fisher test $(p<0.05)$.

CaMKII appears to stand out as a lead candidate for mediating the GluN2B-specific, $\mathrm{Ca}^{2+}$-dependent activation of ERK1/2. We demonstrated that interfering with CaMKII signaling, using inhibitors, shRNA, or mutant overexpression, inhibits the functional link between synaptic NMDAR activation and ERK1/2 phosphorylation. An interesting observation is that the $\alpha$ isoform of CaMKII appears specifically responsible for ERK1/2 activation, since knocking down $\beta$ CaMKII did not impact on ERK1/2 
phosphorylation. This is consistent with the developmental regulation of $\alpha$ CaMKII expression and of the synaptic NMDAR-induced ERK1/2 activation, which coincide temporally. However, $\beta$ CaMKII has nevertheless been shown to be able to bind GluN2B in vitro (Bayer et al., 2006). One possible explanation is that its interaction with F-actin at basal $\mathrm{Ca}^{2+}$ levels (Shen and Meyer, 1999) could slow down its translocation to GluN2B at active synapses. In any case, we showed by immunoprecipitation that GluN2B interacted preferentially with $\alpha$ CaMKII compared with $\beta$ CaMKII. $\alpha$ CaMKII has a long list of potential substrates in neurons (Yoshimura et al., 2002) and some of them control ERK1/2 activation. Indeed previous studies have shown that CaMKII could directly activate Ras/Raf1/MAPkinase pathway (Illario et al., 2003) and more recent evidence have also established a direct MEK1 phosphorylation by CaMKII (Li et al., 2009).

We found that the recruitment of $\alpha$ CaMKII into spines occurred only when the cytosolic $\mathrm{Ca}^{2+}$ increase resulted from the GluN2B-containing NMDAR stimulation. At the synapse, CaMKII binds to several proteins (Colbran and Brown, 2004) and it has been postulated that the association of CaMKII with PSD proteins is necessary for synaptic plasticity (Lisman et al., 2012). Here we provided evidence that the GluN2B/CaMKII interaction is crucial for sustained ERK1/2 activation. First, we confirmed that GluN2B and $\alpha$ CaMKII coimmunoprecipitate and that the kinase is retained in spines following synaptic stimulation (Bayer et al., 2006). This retention was selectively mediated by GluN2B-containing receptor activation and not by GluN2A. Finally, overexpression of $\alpha$ CaMKII mutated (I205K) on the binding site for GluN2B (Bayer et al., 2001, 2006) prevented synaptic NMDAR-induced ERK1/2 activation. How this interaction leads to a sustained ERK1/2 is still unknown. However, the fact that the CaMKII subunits that are bound to GluN2B are locked in an active state for a persistent period (Bayer et al., 2001, 2006) might be critical for supporting the persistent phosphorylation state of ERK1/2. On the other hand, it was shown that autophosphorylation of CaMKII in the spine is short-lived following glutamate uncaging, when the hippocampal network is silenced by TTX (Lee et al., 2009). Those two modes of CaMKII autonomous activity, T286 autophosphorylation and GluN2B binding, could thus have distinct terms and serve different functions inside the spine. The importance of GluN2B NMDAR subunit interaction with $\alpha$ CaMKII in synaptic potentiation has been already demonstrated (Barria and Malinow, 2005; Zhou et al., 2007). The functional link between CaMKII and ERK signaling in LTP was suggested by Zhu et al. (2002), who showed that the MEK inhibitor PD98095 could affect CaMKII-mediated increase in synaptic insertion of AMPARs. Our results bridge those previous findings and unveil a functional relationship between GluN2B- $\alpha$ CaMKII complex and ERK1/2 signaling.

To address the possible implication of this signaling cascade in synaptic plasticity, we focused on spine remodeling and AMPAR recruitment, which have been featured in studies of synaptic plasticity involving CaMKII and ERK (Okamoto et al., 2009; Patterson et al., 2010; Lisman et al., 2012). As previously demonstrated with ERK1/2 inhibitor, we have established that the blockade of GluN2B-containing NMDARs or the CaMKII/GluN2B interaction prevents spine enlargement and synaptic AMPAR recruitment induced by synaptic NMDAR activity. Although changes in spine volume have often been correlated with changes in AMPAR-mediated currents, examples of dissociation between the two processes have been reported (Bagal et al., 2005; Li et al., 2007; Wang and Zhou, 2010). These differences may in part reflect the distinct structural and enzymatic roles that CaMKII has on spines, F-actin dynamics and AMPAR-mediated currents (Okamoto et al., 2009; Wang and Zhou, 2010; Lisman et al., 2012). The critical importance of the $c$ terminus of GluN2B and its binding to CaMKII, but not the c terminus of GluN2A, on synaptic development and maturation has been elegantly demonstrated by swapping their c termini (Wang et al., 2011). Thus, the specific activation of GluN2B-containing NMDARs seems to participate in structural and functional changes in developing circuits, and our study suggests that these processes might involve a GluN2B-CaMKII-ERK1/2 pathway.

The GluN2B-CaMKII complex has been the focus of many studies because of its critical importance in the development of synapses and in their potentiation. Our work highlights the ERK pathway as a downstream link that could mediate the effects driven by this complex. Recently, this complex has also been implicated in the maintenance of LTP, because its disruption with the CN21 peptide reversed LTP (Sanhueza et al., 2011). ERK1/2 signaling has been implicated in translation-dependent maintenance of LTP (Kelleher et al., 2004). Future work should address whether the functional link between GluN2B-CaMKII and ERK1/2 could support the maintenance of LTP. Thus, CaMKII appears to decode synaptic NMDAR activity into an extended active state of ERK1/2, essential for several forms of synaptic plasticity, for certain types of learning, and for cellular changes that are thought to underlie these events (English and Sweatt, 1996, 1997; Atkins et al., 1998; Thomas and Huganir, 2004).

\section{References}

Agell N, Bachs O, Rocamora N, Villalonga P (2002) Modulation of the Ras/ Raf/MEK/ERK pathway by $\mathrm{Ca}(2+)$, and calmodulin. Cell Signal 14:649-654.

Atkins CM, Selcher JC, Petraitis JJ, Trzaskos JM, Sweatt JD (1998) The MAPK cascade is required for mammalian associative learning. Nat Neurosci 1:602-609.

Bading H, Greenberg ME (1991) Stimulation of protein tyrosine phosphorylation by NMDA receptor activation. Science 253:912-914.

Bagal AA, Kao JP, Tang CM, Thompson SM (2005) Long-term potentiation of exogenous glutamate responses at single dendritic spines. Proc Natl Acad Sci U S A 102:14434-14439.

Barria A, Malinow R (2005) NMDA receptor subunit composition controls synaptic plasticity by regulating binding to CaMKII. Neuron 48:289-301.

Bayer KU, De Koninck P, Leonard AS, Hell JW, Schulman H (2001) Interaction with the NMDA receptor locks CaMKII in an active conformation. Nature 411:801-805.

Bayer KU, LeBel E, McDonald GL, O’Leary H, Schulman H, De Koninck P (2006) Transition from reversible to persistent binding of CaMKII to postsynaptic sites and NR2B. J Neurosci 26:1164-1174.

Bellone C, Nicoll RA (2007) Rapid bidirectional switching of synaptic NMDA receptors. Neuron 55:779-785.

Chandler LJ, Sutton G, Dorairaj NR, Norwood D (2001) N-methyl D-aspartate receptor-mediated bidirectional control of extracellular signal-regulated kinase activity in cortical neuronal cultures. J Biol Chem 276:2627-2636.

Chen Q, He S, Hu XL, Yu J, Zhou Y, Zheng J, Zhang S, Zhang C, Duan WH, Xiong ZQ (2007) Differential roles of NR2A- and NR2B-containing NMDA receptors in activity-dependent brain-derived neurotrophic factor gene regulation and limbic epileptogenesis. J Neurosci 27:542-552.

Chwang WB, O'Riordan KJ, Levenson JM, Sweatt JD (2006) ERK/MAPK regulates hippocampal histone phosphorylation following contextual fear conditioning. Learn Mem 13:322-328.

Colbran RJ, Brown AM (2004) Calcium/calmodulin-dependent protein kinase II and synaptic plasticity. Curr Opin Neurobiol 14:318-327.

Di Cristo G, Berardi N, Cancedda L, Pizzorusso T, Putignano E, Ratto GM, Maffei L (2001) Requirement of ERK activation for visual cortical plasticity. Science 292:2337-2340.

English JD, Sweatt JD (1996) Activation of p42 mitogen-activated protein kinase in hippocampal long term potentiation. J Biol Chem 271:24329-24332. 
English JD, Sweatt JD (1997) A requirement for the mitogen-activated protein kinase cascade in hippocampal long term potentiation. J Biol Chem 272:19103-19106.

Foster KA, McLaughlin N, Edbauer D, Phillips M, Bolton A, ConstantinePaton M, Sheng M (2010) Distinct roles of NR2A and NR2B cytoplasmic tails in long-term potentiation. J Neurosci 30:2676-2685.

Fox CJ, Russell KI, Wang YT, Christie BR (2006) Contribution of NR2A and NR2B NMDA subunits to bidirectional synaptic plasticity in the hippocampus in vivo. Hippocampus 16:907-915.

Gardoni F, Caputi A, Cimino M, Pastorino L, Cattabeni F, Di Luca M (1998) Calcium/calmodulin-dependent protein kinase II is associated with $\mathrm{NR} 2 \mathrm{~A} / \mathrm{B}$ subunits of NMDA receptor in postsynaptic densities. J Neurochem 71:1733-1741.

Gladding CM, Raymond LA (2011) Mechanisms underlying NMDA receptor synaptic/extrasynaptic distribution and function. Mol Cell Neurosci 48:308-320.

Gouix E, Léveillé F, Nicole O, Melon C, Had-Aissouni L, Buisson A (2009) Reverse glial glutamate uptake triggers neuronal cell death through extrasynaptic NMDA receptor activation. Mol Cell Neurosci 40:463-473.

Hardingham GE, Bading H (2002) Coupling of extrasynaptic NMDA receptors to a CREB shut-off pathway is developmentally regulated. Biochim Biophys Acta 1600:148-153.

Harris AZ, Pettit DL (2008) Recruiting extrasynaptic NMDA receptors augments synaptic signaling. J Neurophysiol 99:524-533.

Hudmon A, Lebel E, Roy H, Sik A, Schulman H, Waxham MN, De Koninck P (2005) A mechanism for $\mathrm{Ca}^{2+} /$ calmodulin-dependent protein kinase II clustering at synaptic and nonsynaptic sites based on self-association. J Neurosci 25:6971-6983.

Illario M, Cavallo AL, Bayer KU, Di Matola T, Fenzi G, Rossi G, Vitale M (2003) Calcium/calmodulin-dependent protein kinase II binds to Raf-1 and modulates integrin-stimulated ERK activation. J Biol Chem 278:45101-45108.

Izumi Y, Auberson YP, Zorumski CF (2006) Zinc modulates bidirectional hippocampal plasticity by effects on NMDA receptors. J Neurosci 26:7181-7188.

Jin SX, Feig LA (2010) Long-term potentiation in the CA1 hippocampus induced by NR2A subunit-containing NMDA glutamate receptors is mediated by Ras-GRF2/Erk map kinase signaling. PloS One 5:e11732.

Kelleher RJ 3rd, Govindarajan A, Jung HY, Kang H, Tonegawa S (2004) Translational control by MAPK signaling in long-term synaptic plasticity and memory. Cell 116:467-479.

Kim MJ, Dunah AW, Wang YT, Sheng M (2005) Differential roles of NR2Aand NR2B-containing NMDA receptors in Ras-ERK signaling and AMPA receptor trafficking. Neuron 46:745-760.

Kirson ED, Yaari Y (1996) Synaptic NMDA receptors in developing mouse hippocampal neurones: functional properties and sensitivity to ifenprodil. J Physiol 497:437-455.

Köhr G (2006) NMDA receptor function: subunit composition versus spatial distribution. Cell Tissue Res 326:439-446.

Krapivinsky G, Krapivinsky L, Manasian Y, Ivanov A, Tyzio R, Pellegrino C, Ben-Ari Y, Clapham DE, Medina I (2003) The NMDA receptor is coupled to the ERK pathway by a direct interaction between NR2B and RasGRF1. Neuron 40:775-784.

Lee SJ, Escobedo-Lozoya Y, Szatmari EM, Yasuda R (2009) Activation of CaMKII in single dendritic spines during long-term potentiation. Nature 458:299-304.

Legendre P, Westbrook GL (1991) Ifenprodil blocks $N$-methyl-D-aspartate receptors by a two-component mechanism. Mol Pharmacol 40:289-298.

Leonard AS, Lim IA, Hemsworth DE, Horne MC, Hell JW (1999) Calcium/ calmodulin-dependent protein kinase II is associated with the $\mathrm{N}$-methylD-aspartate receptor. Proc Natl Acad Sci U S A 96:3239-3244.

Léveillé F, El Gaamouch F, Gouix E, Lecocq M, Lobner D, Nicole O, Buisson A (2008) Neuronal viability is controlled by a functional relation between synaptic and extrasynaptic NMDA receptors. FASEB J 22:4258-4271.

Li B, Woo RS, Mei L, Malinow R (2007) The neuregulin-1 receptor erbB4 controls glutamatergic synapse maturation and plasticity. Neuron 54:583-597.

Li N, Wang C, Wu Y, Liu X, Cao X (2009) Ca(2+)/calmodulin-dependent protein kinase II promotes cell cycle progression by directly activating MEK1 and subsequently modulating p27 phosphorylation. J Biol Chem 284:3021-3027.
Lin YC, Redmond L (2008) CaMKIIbeta binding to stable F-actin in vivo regulates F-actin filament stability. Proc Natl Acad Sci U A 105:15791-15796.

Lisman J, Yasuda R, Raghavachari S (2012) Mechanisms of CaMKII action in long-term potentiation. Nat Rev Neurosci 13:169-182.

Liu L, Wong TP, Pozza MF, Lingenhoehl K, Wang Y, Sheng M, Auberson YP, Wang YT (2004) Role of NMDA receptor subtypes in governing the direction of hippocampal synaptic plasticity. Science 304:1021-1024.

Massey PV, Johnson BE, Moult PR, Auberson YP, Brown MW, Molnar E, Collingridge GL, Bashir ZI (2004) Differential roles of NR2A and NR2B-containing NMDA receptors in cortical long-term potentiation and long-term depression. J Neurosci 24:7821-7828.

Neyton J, Paoletti P (2006) Relating NMDA receptor function to receptor subunit composition: limitations of the pharmacological approach. J Neurosci 26:1331-1333.

Okamoto K, Narayanan R, Lee SH, Murata K, Hayashi Y (2007) The role of CaMKII as an F-actin-bundling protein crucial for maintenance of dendritic spine structure. Proc Natl Acad Sci U S A 104:6418-6423.

Okamoto K, Bosch M, Hayashi Y (2009) The roles of CaMKII and F-actin in the structural plasticity of dendritic spines: a potential molecular identity of a synaptic tag? Physiology (Bethesda) 24:357-366.

Opazo P, Labrecque S, Tigaret CM, Frouin A, Wiseman PW, De Koninck P, Choquet D (2010) CaMKII triggers the diffusional trapping of surface AMPARs through phosphorylation of stargazin. Neuron 67:239-252.

Otmakhov N, Tao-Cheng JH, Carpenter S, Asrican B, Dosemeci A, Reese TS, Lisman J (2004) Persistent accumulation of calcium/calmodulindependent protein kinase II in dendritic spines after induction of NMDA receptor-dependent chemical long-term potentiation. J Neurosci 24:9324-9331.

Pacchioni AM, Vallone J, Worley PF, Kalivas PW (2009) Neuronal pentraxins modulate cocaine-induced neuroadaptations. J Pharmacol Exp Ther 328:183-192.

Patterson MA, Szatmari EM, Yasuda R (2010) AMPA receptors are exocytosed in stimulated spines and adjacent dendrites in a Ras-ERKdependent manner during long-term potentiation. Proc Natl Acad Sci U S A 107:15951-15956.

Pi Hj, Otmakhov N, El Gaamouch F, Lemelin D, De Koninck P, Lisman J (2010) CaMKII control of spine size and synaptic strength: role of phosphorylation states and non enzymatic action. Proc Natl Acad Sci U S A 107:14437-14442.

Rose K, Goldberg MP, Choi DW (1993) Cytotoxicity in murine neocortical cell culture. Methods Toxicol 1:15

Sanhueza M, Fernandez-Villalobos G, Stein IS, Kasumova G, Zhang P, Bayer KU, Otmakhov N, Hell JW, Lisman J (2011) Role of the CaMKII/ NMDA receptor complex in the maintenance of synaptic strength. J Neurosci 31:9170-9178.

Schmitt JM, Wayman GA, Nozaki N, Soderling TR (2004) Calcium activation of ERK mediated by calmodulin kinase I. J Biol Chem 279:24064-24072.

Shen K, Meyer T (1999) Dynamic control of CaMKII translocation and localization in hippocampal neurons by NMDA receptor stimulation. Science 284:162-166.

Sobczyk A, Scheuss V, Svoboda K (2005) NMDA receptor subunitdependent $\left[\mathrm{Ca}^{2+}\right]$ signaling in individual hippocampal dendritic spines. J Neurosci 25:6037-6046.

Steward O, Huang F, Guzowski JF (2007) A form of perforant path LTP can occur without ERK1/2 phosphorylation or immediate early gene induction. Learn Mem 14:433-445.

Strack S, Colbran RJ (1998) Autophosphorylation-dependent targeting of calcium/ calmodulin-dependent protein kinase II by the NR2B subunit of the $N$-methyl-D-aspartate receptor. J Biol Chem 273:20689-20692.

Sweatt JD (2001) The neuronal MAP kinase cascade: a biochemical signal integration system subserving synaptic plasticity and memory. J Neurochem 76:1-10.

Sweatt JD (2004) Mitogen-activated protein kinases in synaptic plasticity and memory. Curr Opin Neurobiol 14:311-317.

Sweatt JD (2009) Experience-dependent epigenetic modifications in the central nervous system. Biol Psychiatry 65:191-197.

Thomas CG, Miller AJ, Westbrook GL (2006) Synaptic and extrasynaptic NMDA receptor NR2 subunits in cultured hippocampal neurons. J Neurophysiol 95:1727-1734 
Thomas GM, Huganir RL (2004) MAPK cascade signalling and synaptic plasticity. Nat Rev Neurosci 5:173-183.

Tolias KF, Duman JG, Um K (2011) Control of synapse development and plasticity by Rho GTPase regulatory proteins. Prog Neurobiol 94:133-148.

Tovar KR, Westbrook GL (1999) The incorporation of NMDA receptors with a distinct subunit composition at nascent hippocampal synapses in vitro. J Neurosci 19:4180-4188.

Traynelis SF, Wollmuth LP, McBain CJ, Menniti FS, Vance KM, Ogden KK, Hansen KB, Yuan H, Myers SJ, Dingledine R (2010) Glutamate receptor ion channels: structure, regulation, and function. Pharmacol Rev 62:405-496.

Vest RS, Davies KD, O’Leary H, Port JD, Bayer KU (2007) Dual mechanism of a natural CaMKII inhibitor. Mol Biol Cell 18:5024-5033.

von Engelhardt J, Doganci B, Jensen V, Hvalby Ø, Göngrich C, Taylor A, Barkus C, Sanderson DJ, Rawlins JN, Seeburg PH, Bannerman DM, Monyer H (2008) Contribution of hippocampal and extra-hippocampal NR2B-containing NMDA receptors to performance on spatial learning tasks. Neuron 60:846-860.

Wang CC, Held RG, Chang SC, Yang L, Delpire E, Ghosh A, Hall BJ (2011) A critical role for GluN2B-containing NMDA receptors in cortical development and function. Neuron 72:789-805.

Wang JQ, Tang Q, Parelkar NK, Liu Z, Samdani S, Choe ES, Yang L, Mao L (2004) Glutamate signaling to Ras-MAPK in striatal neurons: mechanisms for inducible gene expression and plasticity. Mol Neurobiol 29:1-14.

Wang XB, Zhou Q (2010) Spine remodeling and synaptic modification. Mol Neurobiol 41:29-41.

Wayman GA, Lee YS, Tokumitsu H, Silva AJ, Soderling TR (2008) Calmod- ulin-kinases: modulators of neuronal development and plasticity. Neuron 59:914-931.

Winder DG, Martin KC, Muzzio IA, Rohrer D, Chruscinski A, Kobilka B, Kandel ER (1999) ERK plays a regulatory role in induction of LTP by theta frequency stimulation and its modulation by beta-adrenergic receptors. Neuron 24:715-726.

Xiao L, Hu C, Feng C, Chen Y (2011) Switching of N-methyl-D-aspartate (NMDA) receptor-favorite intracellular signal pathways from ERK1/2 protein to $\mathrm{p} 38$ mitogen-activated protein kinase leads to developmental changes in NMDA neurotoxicity. J Biol Chem 286:20175-20193.

Yoshimura Y, Shinkawa T, Taoka M, Kobayashi K, Isobe T, Yamauchi T (2002) Identification of protein substrates of $\mathrm{Ca}(2+) /$ calmodulindependent protein kinase II in the postsynaptic density by protein sequencing and mass spectrometry. Biochem Biophys Res Commun 290:948-954.

Yoshimura Y, Ohmura T, Komatsu Y (2003) Two forms of synaptic plasticity with distinct dependence on age, experience, and NMDA receptor subtype in rat visual cortex. J Neurosci 23:6557-6566.

Zhao MG, Toyoda H, Lee YS, Wu LJ, Ko SW, Zhang XH, Jia Y, Shum F, Xu H, Li BM, Kaang BK, Zhuo M (2005) Roles of NMDA NR2B subtype receptor in prefrontal long-term potentiation and contextual fear memory. Neuron 47:859-872.

Zhou Y, Takahashi E, Li W, Halt A, Wiltgen B, Ehninger D, Li GD, Hell JW, Kennedy MB, Silva AJ (2007) Interactions between the NR2B receptor and CaMKII modulate synaptic plasticity and spatial learning. J Neurosci 27:13843-13853.

Zhu JJ, Qin Y, Zhao M, Van Aelst L, Malinow R (2002) Ras and Rap control AMPA receptor trafficking during synaptic plasticity. Cell 110:443-455. 